\title{
NON-PYTHAGOREAN PROPORTIONS AND THE DIAPASÓN IN THE DESIGN OF IBERIAN HARPSICHORD SCALES
}

\author{
Paul Poletti \\ Escola Superior de Música de Catalunya (ESMUC)
}

\begin{abstract}
:
One of the tenets of modern organology is that the strings of keyboard instruments have generally been designed according to the theory that length is in versely proportional to pitch, resulting in a progression of string lengths kno wn as a Pythagorean Scale. Recent research has begun to focus on surviving Iberian instruments, heretofore largely neglected. While few have survived, it would appear that a significant number of their builders had a tendency to employ non-Pythagorean scales.

One recent study suggests that these instruments represent a curious collecti ve adherence to archaic methods used in the design of Medieval instruments. The present article of fers an alternative viewpoint, showing how such scales could easily ha ve been constructed using a traditional organ builder's design tool, called a Diapasón. The geometric logic of the Diapasón is briefly explained as well as the $\mathrm{v}$ arious progressions which can result from its use. The scales of se veral Iberian instruments are then examined in light of these alternative methods, arriving at the conclusion that their makers, rather than exhibiting an archaic conservatism, actually formed part of growing $18^{\text {th }}$ century movement towards the use of extended non-Pythagorean scales as are now ubiquitously found in the modern piano.
\end{abstract}

\section{Key words:}

Iberian, Spain, harpsichord, organ, design, strings, wire, Pythagorean, scale, Diapason, Fernández, Santos, Bueno.

\section{Resumen:}

Uno de los principios de la organología moderna es que las cuerdas de los instrumentos de teclado se han diseñado generalmente según la teoría que la longitud es inversamente proporcional al tono, dando por resultado una progresión de las longitude $\mathrm{s}$ de la secuencia conocidas como escala pitagórica. La in vestigación reciente ha comenzado a centrarse en los instrumentos ibéricos supervivientes, descuidados hasta ahora en gran parte. Mientras que pocos han sobre vivido, se ha constatado que un número significativo de sus constructores tenía una tendencia a emplear escalas no-Pitagóricas. Un estudio reciente sugiere que estos instrumentos representen una adherencia colectiva curiosa a los métodos arcaicos usados en el diseño de instrumentos medieales. El artículo presente ofrece un punto de vista alternati vo, demostrando cómo tales escalas se habrían podido construir fácilmen te usando una herramienta de diseño tradicional para construir ór ganos, llamada Diapasón. La lógica geométrica del Diapasón es explicada brevemente, así como varias progresiones que pueden resultar de su uso. Las escalas de arios instrumentos ibéricos son examinadas a la luz de estos métodos alternativos, llegando la conclusión de que sus fabricantes, exhibiendo un conservadurismo arcaico, formaron realmente un movimiento cada vez mayor del siglo xvIII hacia el uso de escalas no-Pitagóricas extendidas, como ahora se encuentran de forma ubicua en el piano moderno.

Palabras clave:

Ibérico, España, clavicémbalo, órgano, diseño, cuerdas de piano, escalas Pitagóricas, Diapasón, Fernández, Santos, Bueno. 
The Iberian harpsichord has recently beun to receive an ever increasing amount of attention from historical organologists after an initial period of relati ve neglect in the early decades of the modern harpsichord revival. The newest addition to this rapidly gro wing body of literature is John K oster's examination of the w ork of a handful of instruments representing the Valladolid school, in which he uses these e xamples as a springboard for e xamining the Iberian harpsichord's hypothetical lineage within the larger context of European harpsichord making. K oster illustrates how the Iberian mak ers drew various elements of style and design from other schools of making, most notably Flemish and Italian ${ }^{1}$. One aspect, however, is singled out by Koster as being unique: the design of the lengths of the instruments" strings, or the "scale" as it is usually called.

Koster's reasoning is based on the hypothesis that so-called "Pythagorean" scaling, in which the lengths of the strings follow a reduction which is in versely proportional to the fundamental frequencies they sound, is the basis of all non-Iberian harpsichord making (with a fe w occasional exceptions found mostly in rectangular virginals). A significant number of the surviving Valladolid harpsichords, however, have markedly non-Pythagorean scales. Since the avareness of Pythagorean proportions was omnipresent in European culture, Koster argues, these Iberian makers must have had some extraordinary motivation for their "collecti ve indifference to the niceties of scaling as practiced almost e verywhere else" ${ }^{2}$. His hypothesis is that these Iberian mak ers may ha ve been emplo ying archaic design practices hark ening back to Medieval examples, using large circular arcs to define the shape of the instrument's bridge, and points to the f act that such methods were still commonly emplo yed in the 17th and 18th centuries in architectural design and the construction of buildings. He concludes his article with a recreation of how one of these builders, Joseph Bueno, might have drawn his bridge shape in just such a manner, using two large arcs with centers well outside the boundary of the instrument, the first, with a radius of about 100 $\mathrm{cm}$, defining the upper half of the scale, and the second, with a radius of about $270 \mathrm{~cm}$, defining the tenor portion until the sharp turn towards the spine, called the "bass hook".

The present article presents a different view, demonstrating that while Pythagorean scaling does indeed seem to be the ideal for the Italian school, non-Pythagorean scales are not as rare in northern European instrument making as $\mathrm{K}$ oster posits. When vie wed against this broader vision of what constitutes "normality", it becomes evident that, rather than representing a curious hark ening back to "archaic" practices from the 15th century, these Valladolid makers were actually scaling their strings in a manner similar to more adv anced builders working elsewhere in Europe, employing design aspects which would eventually become adopted by all modern piano mak ers in the second half of the 19th century. In addition, it is demonstrated ho w a methodology commonly emplo yed by or gan makers perfectly explains the peculiar shape of all bt one of the non-Pythagorean scales found in th\&alladolid instruments. The number of truly puzzling scales is reduced to those of only tw o instruments, and a

1 Koster, John: "Traditional Iberian Harpsichord Making in its European Conte xt", in The Galpin Society Journal, LXI (2008), pp. 3-78.

2 Koster, John: op. cit., p. 22. 
brief demonstration is of fered for one of them as an e xample of how the knowledge of such design procedures might be applied to arriving at a credible explanation for this type of scale.

Generally speaking, harpsichord scales are thought to be of totypes: (1) those which are completely Pythagorean for all (or almost all) of the strings, and (2) those which are Pythagorean only in the upper half of the instrument, the rest of the strings being progressively "foreshortened" (going downwards into the bass) from their "theoretically correct" Pythagorean lengths. Type 1 is considered to be generally characteristic of Italian instruments, assumed to be strung in brass, and Type 2 characteristic of northern instruments strung with iron in the treble and brass in the bass.The basic reasoning behind this difference is that brass, being a weaker material, requires a scale which is generally shorter than for iron strings, and since the scale is generally short, the string lengths can continue to double for e very octave of descent. Iron, being a stronger material, is generally capable of taking a longer o verall scale, usually about four semitones or approximately $25 \%$ longer. However, precisely because the basic scale is so much longer, if the tenor and bass strings were to continue to double at e very octave as demanded by Pythagorean proportions, the instrument would become unmanageably long.

Two instruments which demonstrate these hypothetical "ideal" curv es are shown in Fig. 1a-b ${ }^{3}$. These graphics, which will be used throughout the course of this article, illustrate the structure of a scale in both absolute and proportional terms ${ }^{4}$. Actual string lengths are read in millimeters along the left axis, and a solid curve indicates the supposed Pythagorean design cure. Another trace indicates the proportional deviation from this ideal design curve, expressed in semitones, read along the right axis. This dual graphing allo ws the eye to instantly judge the real shape of the curv e against its proposed underlying design shape as well as the mechanical/acoustical significance of any absolute aberration, which is proportional ${ }^{5}$. For example, a deviation of $20 \mathrm{~mm}$ between the actual and ideal string length at $\mathrm{c}^{3}$ of is significant in both absolute and proportional terms, being a difference of two semitones; on the other hand, the same de viation of $20 \mathrm{~mm}$ three octa ves lower, at tenor c, is hardly w orth noting,

3 The instruments are the 1599 Celestini (Fig. 1a) in the Museum für K unst und Gewerbe, Hamburg (2000, p. 509), and the 1772 Shudi \& Broadw ood (Fig. 1b) in the Museum of Fine Arts, Boston (1977, p. 57). The string lengths are tak en from Beurman, Andreas: Historisches Tasteninstrumente. München, Prestel, 2000, and Koster, John: Keyboard Musical Instruments in the Museum of Fine Arts. Boston, Museum of Fine Arts, 1994.

4 The data for the instruments presented in this article come from a variety of sources; in some cases, the length of every note was known, but in others, only the lengths of a small number of notes were reported in the literature, and the rest of thestring lengths were extrapolated by spline curve fitting methods. In the latter case, the reported lengths are indicated by lar ger outlines for the individual plot points on both the absolute and proportional traces. Whenever such indications are absent, the analysis was done with measured lengths of every note.

5 Proportional deviation curves in units of semitones are, in my opinion, the best method of judging the design aspects of any scale, for the y make subtle changes in scaling v ector immediately obvious to the eye. This method of analyzing instrument scales was developed by me in the early 1990's. By contrast, the often encountered logarithmic plot of string lengths, despite its proportional basis, suffers from a number of drawbacks: first, the scale of the display is far too small, making it all but impossible observe the overall shape or any localized alterations within the scale; secondly the data plots all run at highly oblique anges to the vertical axis, meaning that it is exceedingly difficult for the eye to correctly judge the magnitude of the vertical distance between any two plots ; and finally, the basic unit of visual measure (log length) has no immediate relationship with rele vant aspect of the physical object under study, in that while one may be able to see a certain distance between traces, the graphical representation alone provides no way to judge its significance. In essence, log plots male all but the most markedly deviant scales appear to "more or less" follow Pythagorean proportions, and their common use may well be one of the reasons why modern or ganologists have generally missed the existence of many non-Pythagorean scaled instruments. 
as it represents a functional de viation of only about one-third semitone ${ }^{6}$. Furthermore, as can be seen by observing the general shape of the bridge in the tenor re gion, because of the highly oblique angle of the bridge relative to the strings, the slightest de viation to the left or right of the ideal position can cause rather lar ge absolute de viations in string lengths. This fact, when combined with the reduced proportional significance, means that we should accept aberrations which are much lar ger in absolute terms in the tenor regions than in the treble when evaluating the credibility of any hypothetical design ideal.

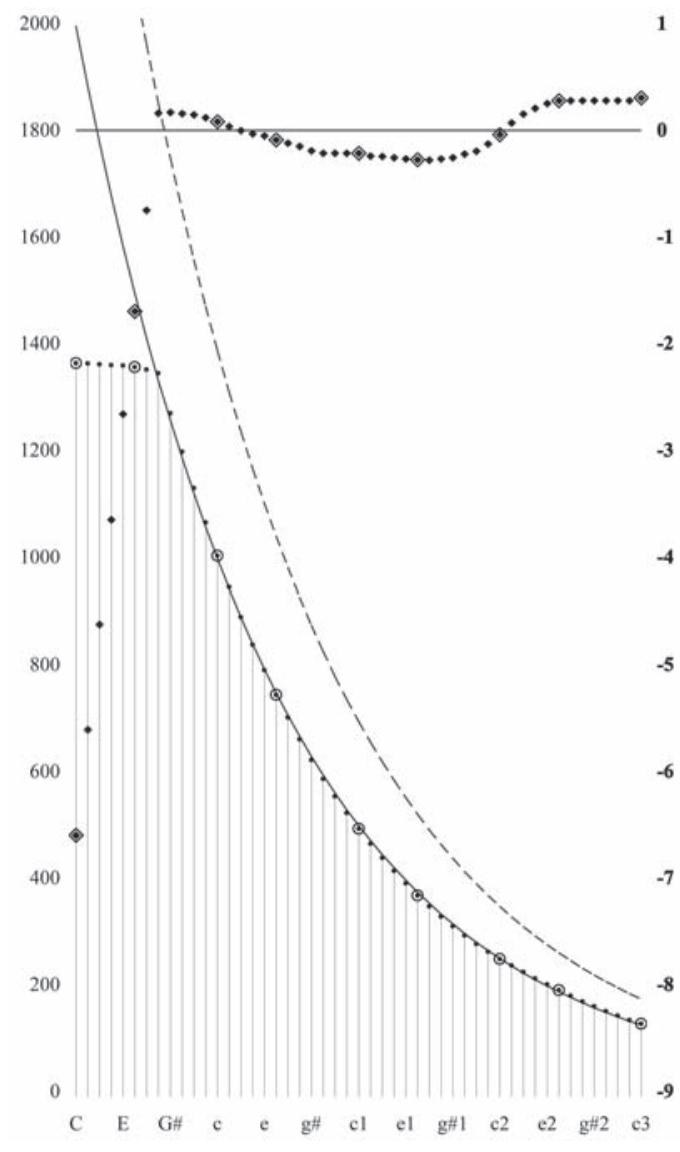

Figure 1a. Celestini, 1599.

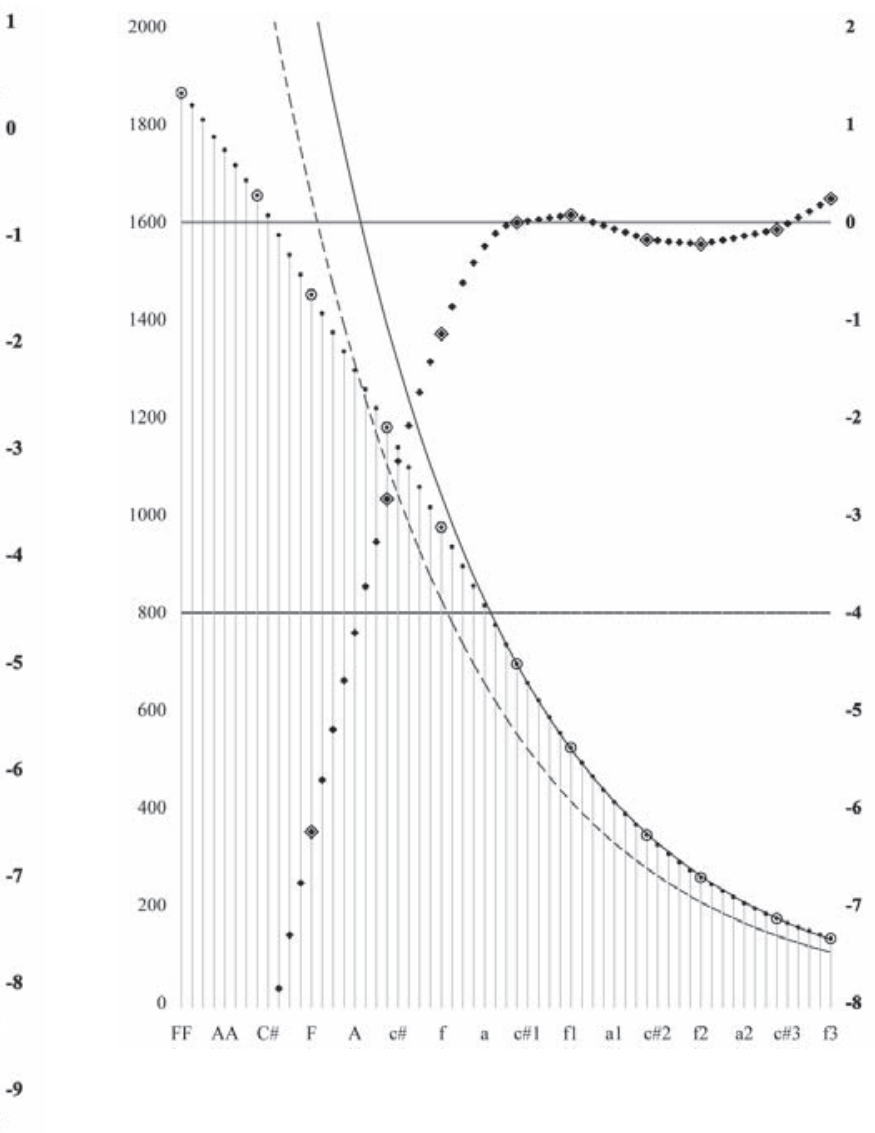

Figure 1b. Shudi \& Broadwood, 1722.

6 Throughout this article I use the Helmholtz-based system of pitch notation $\left(\mathrm{CC}, \mathrm{C}, \mathrm{c}, \mathrm{c}^{1}\right.$, $\mathrm{c}^{2}$, etc), not only because it is the most commonly used system among stringed keyboard organologists, but also to avoid any confusion between the arguments and data presented here and those presented in the various cited works. Additionally, it has the advantage of being compatible with many historical documents. 
In both of the instruments, there are minor de viations from the ideal curv e, possibly caused by original workshop error or distortion of the instrument oer the centuries. Nonetheless, the errors are very small both in absolute and proportional terms, and the original intent is therefore quite clearThe scale of the Celestini is Pythagorean until the sudden deviation of the "bass hook" for the last seven notes. While such drastic "foreshortening" of the lo wer notes is not uncommon, Italian instruments often continue to follow a strict Pythagorean progression much further into the bass. This instrument, for e xample, would have a bottom string about two meters long if "correctly" scaled; some Italian instruments which have larger compasses can arri ve to string lengths of almost $230 \mathrm{~cm}$. F or comparison, a dashed trace indicates the Pythagorean curv e of the Schudi/Broadw ood iron-strung portion, sho wing how an ironstrung instrument, if made with Pythagorean proportions deep into the bass, would be even longer yet.

The Shudi/Broadwood is strung in iron in the treble and therefore has a generally longer design curve. The scale is therefore Pythagorean only above $\mathrm{c}^{1}$, and from there down, the notes are gradually foreshortened, the bridge more or less follo wing a straight line. When the strings reach the general length of a brass Pythagorean scale (indicated by a dashed line), the stringing material changes from iron to brass, which is then used for the remainder of the lower notes.

Koster presents a number of e xamples which adhere to this sort of scheme from the Flemish, German, and English schools, and briefly outlines the supposed design methodology behind all such instruments ${ }^{7}$. The assumption is that the method used by Ruck ers was practiced universally; a length was determined for the top note of the instrument, usually $\mathrm{c}^{3}$ in the early instruments, and $\mathrm{w}$ as then doubled twice to obtain the lengths of the notes $\mathrm{c}^{2}$ and $\mathrm{c}^{1}$ (with some occasional minor $\mathrm{v}$ ariation at $\mathrm{c}^{1}$ ). These three octaves of the note $\mathrm{c}$ were the "key notes" which the maker used both conceptually to design the scale and practically to actually mark the position of the bridge on the soundboard. If desired, other key notes may have been calculated for greater accuracy during bridge placement, using simple Pythagorean proportions; the lengths for the octa ves of $\mathrm{f}$, for example, can be derived by multiplying any of the c lengths by 1,5 and then halving and doubling for all other octa ves. Koster concludes his examination of "typical" northern scaling by summarizing that "the uni versal principle incorporated in all these scaling recipes was that the upper half of the compass should be Pythagorean, with strings doubling in length for each lower octave from $\mathrm{c}^{3}$ down to $\mathrm{c}^{1}$. Even when the actual $\mathrm{c}^{1}$ string was made a little shorter, the scaling remained close to the theoretical ideal down to about $\mathrm{fl}$ "

While all of K oster's examples are 16th and 17th century instruments, I ha ve chosen an 18th century harpsichord to illustrate Type 2 . The Iberian harpsichords under examination are also 18 th century. This fact is not insignificant, for starting in the closing decades of the 1600's, it becomes less easy to find examples of scales in northern European instruments which adhere to strict Pythagorean proportions from around middle $\mathrm{c}^{1}$ all the $\mathrm{w}$ ay to the top note. Instead, we often find significant deviations in the upper re gions, significant in that the $\mathrm{y}$ are too great and the original intent is too

7 Koster, John: “Traditional Iberian...”, op. cit., pp. 24-27.

8 Koster, John: "Traditional Iberian...", op. cit., p. 27 
evident in order to e xplain them a way either as w orkshop error or subsequent distortion. The clear majority of these deviations involve a region near the top of the instrument which has been purposely "stretched", that is, the lengths have been augmented beyond the supposed Pythagorean design lengths. In the mildest of cases, this stretch is only about a semitone, but many instruments demonstrate trebles with are augmented by as much as two or three semitones. Figure 2 shows a noteworthy example, the Taskin instrument from the Russell Collection in Edinb urgh ${ }^{9}$. Here, lik e the Shudi/Broadw ood, the Pythagorean section clearly begins at $\mathrm{c}^{1}$, but in this case, it spans only about an octae and a fifth. From $\mathrm{f}^{2}$, the last octa ve has clearly been augmented until $\mathrm{f}^{3}$ is tw o semitones longer than the main part of the curve. This deviation might be considered a fluke were it not for the existence of at least two other instruments by Taskin with exactly the same deviation in the high treble ${ }^{10}$.

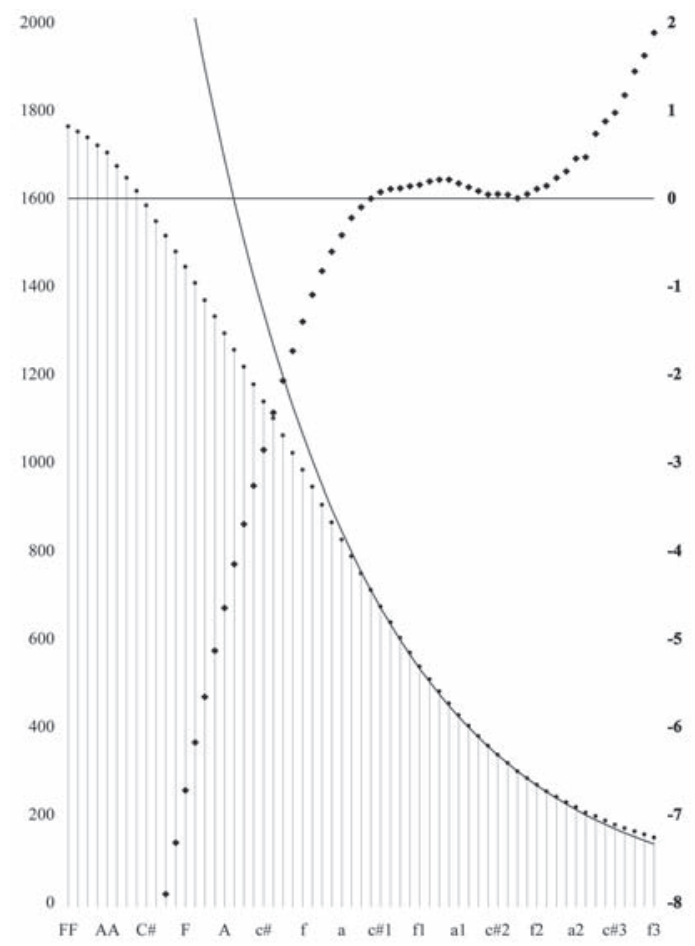

Figure 2. Taskin, 1769.

9 String lengths were taken from the data sheet published on the web site of Edinb urgh University Collection of Historic Musical Instruments: http://www.music.ed.ac.uk/euchmi/uck/uckd4315.html

10 These instruments are the 1782 double in Colares, Portugal, and the 1787 double in the Museum fürukst und Gewerbe, Hamburg, Inv. Nr. 2000,532. They are described in Brauchl, Bernard: "The 1782 Taskin Harpsichord, Colares, Portugal", in The Galpin Society Journal, LIII (2000), pp. 25-50, and Beurman, Andreas: Historisches Tasteninstrumente. Op. cit. Scale analysis by the author using the data provided in the relevant source literature. 
The scales of such instruments still might be considered "essentially Pythagorean" in their upper half in that the mak er could ha ve designed them by using simple Pythagorean proportions for the notes $\mathrm{c}^{1}, \mathrm{f}^{1}$, and $\mathrm{c}^{2}$, plus some method of adding a little amount for $\mathrm{c}^{3}$ and/or $\mathrm{f}^{3}$. However, a number of instruments simply cannot be considered as ha ving anything like Pythagorean proportions as the basis for the treble half of their scales. Two examples which are exceptionally instructive can be found in one and the same instrument, the 1777 combination harpsichord/fortepiano or $\quad V i s-a$-vis built by Stein, now in Verona ${ }^{11}$. This large rectangular instrument has $\mathrm{k}$ eyboards at both ends, resembling a harpsichord and a piano joined along their bentsides. This instrument gives us a unique opportunity to compare the scaling of harpsichords and pianos at a time when both were being made by eliminating all possible incongruities which could result from dif ferences of time, place, mak er and pitch le vel; the only difference here is that the piano is more heavily strung than the harpsichord ${ }^{12}$. Figure 3 shows

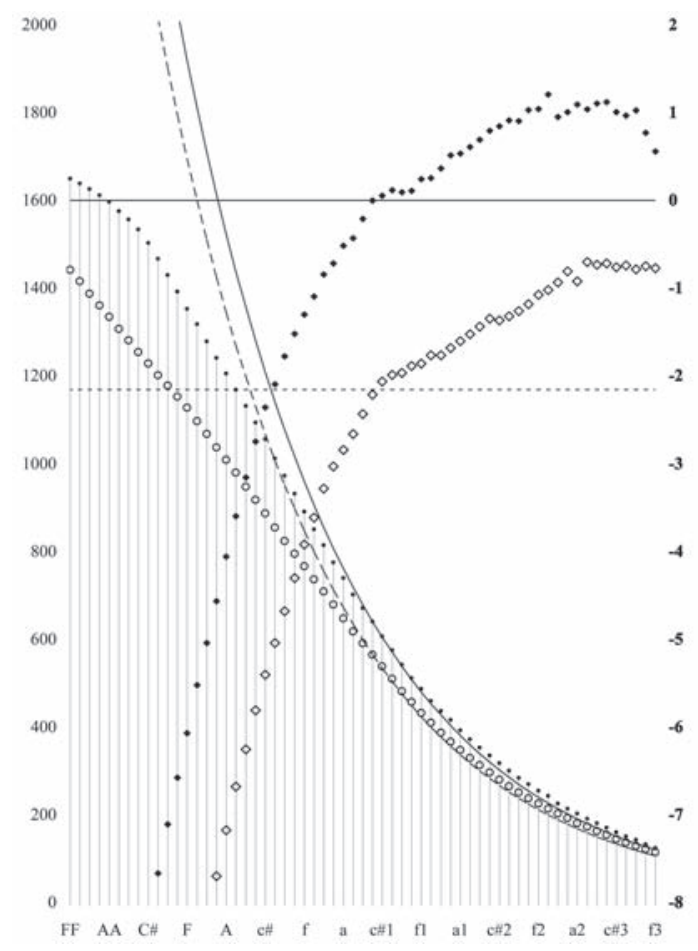

Figure 3. Stein, 1777.

11 The instrument is from the collection of the Museo di Castelv ecchio, currently on loan to the Accademia Filhamonica di Verona. The string lengths were kindly provided to me by Michael Latcham.

12 The harpsichord has gauge marks, bit the piano does not. Hovever, there is more than enough eidence that Stein strung his pianos mark edly heavier, both from other instruments of his which do ha ve gauge marks, and from the stringing schedules notated in his diary. See Latcham, Michael: The Stringing, Scaling and Pitch of Hammerflügel built in the Southern German and Viennese Traditions 1780-1820. München, Katzbichler, 2000, p. 51. 
the scales of both halv es of the instrument with corresponding Pythagorean curv es generated from their respective $\mathrm{c} 1$ notes. Three points are immediately obvious: (1) the difference between the overall lengths is almost exactly two semitones; (2) in both cases foreshortening clearly begins at the note $\mathrm{c}^{1}$; (3) the shapes of the curv es for the treble half of the instrument(s) are almost identical, follo wing a markedly non-Pythagorean re gular logarithmic progression with an octa ve ratio of about 1,9:1 until leveling-off at about $\mathrm{c}^{3}$. The fact that these tw o scales are quite consistent in their strict logarithmic nature while being precisely tw o semitones apart in o verall length implies that Stein w as calculating his string lengths using some method that gave him irrational numbers; that is, he was not working in simple units of any local measuring system.

Finally, to show that Stein w as by no means alone in using truly non-Pythagorean augmented scales, Figure 4 shows two other instruments with similar curv es ${ }^{13}$. Despite being the product of tw o different national schools and separated by almost 50 years, these tw o scales are remarkably similar. Due to the slopes of these curves, it is difficult to say with absolute certainty where the foreshortened tenor ends and the treble scale logic be gins, though both scales seem to mak e a change of $\mathrm{v}$ ector around tenor c. Both scales follo w decidedly non-Pythagorean progressions for most of the treble. As with Stein, the near straight-line v ectors for a significant portion of the de viation curve indicates that the progression are logarithmic; the dashed lines indicate a re gular progression with an octa ve proportion of 1,82:1. In a similar manner to Stein, both scales appear to finally level-off at about $\mathrm{f}^{2}$, more or less follo wing a "normal" Pythagorean progression for the highest octa ve only. Once again, the near perfection of these slopes over a range of two octaves would indicate that both builders were using some means of calculation which allo wed them to operate freely within a uni verse of irrational numbers, rather than being sla ves to the often assumed methodology of calculating scales using only whole units or simple fractions of a local measuring unit.

Before continuing with a detailed analysis of the scales of the Iberian instruments, ha ving demonstrated that northern European builders were not unfamiliar with the concept of non-Pythagorean scales, it would be beneficial to briefly consider the possible motivations behind the use of augmented scales. When an instrument mak er sets out to design the lengths for the series of notes comprising a musical scale of se veral octaves, he must operate within the bounds of tw o extremes: strings which are too long, producing a tension which w ould cause the strings to break before the y could be tuned at the desired pitch, and strings which are too short, meaning that the tension level is far below that at which the strings would break. While the maximum length is easy to determine both theoretically and practically, defining a tension level which is "too low" is extremely difficult. In fact, there is no hard and fast rule which can be adopted, neither theoretically nor one which can be obsered in real instruments. While the lowest notes of almost all instruments are markedly too short, this study is limited primarily to the upper regions of the scale and the transitional zone to the tenor foreshortening (when present).

13 The instruments are the 1691 Vincent Tibaut in the Musée de la musique, $\mathrm{P}$ aris (E.977.11.1), and the 1739 Johann Heinrich Gräbner Jr. in the Kunstgewerbemuseum, Schloß Pillnitz, Dresden (37414). String lengths of the Tibaut are taken from the museum drawing, those of the Gräbner were kindly provided to me by John Phillips. 
Within these regions, a tension level which is too low can cause a number of undesirable phenomena, including a high degree of inharmonicity, problematic interaction with the excitement mechanism (be it hammer or quill), poor tuning stability with $\mathrm{v}$ ariations in temperature and humidity, difficulty in tuning, and a noticeable drop in pitch as the tone decays from the initial moment of attack ${ }^{14}$.

It is a generally accepted tenet of modern organology, therefore, that string lengths for the treble portions of an instrument were chosen in order to maintain the highest practical tension level possible at the design pitch, meaning that the strings were tensioned to a leel almost at which they would break, with only a small safety margin ${ }^{15}$. The issue is often clouded by a common confusion between tension and stress (or load), two related though separate aspects of scale design.Tension is the absolute amount

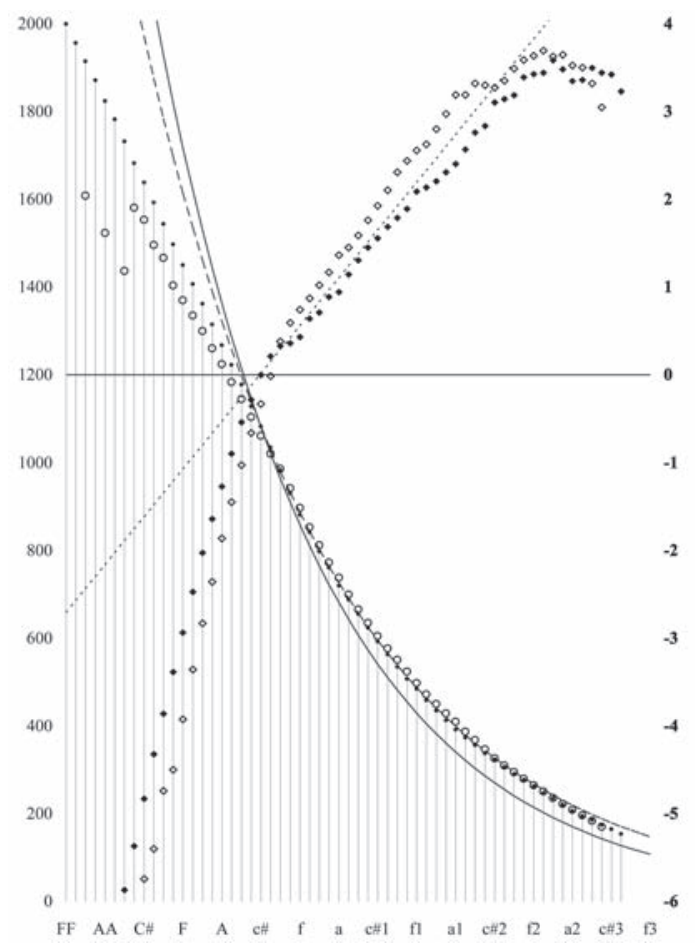

Figure 4. Tibaut, 1691 (white plots) and Gräbner, 1739 (black plots).

14 The usual justification for avoiding low tension is limited to inharmonicity, but this is probably the least important of the various factors. The others listed above are all related to how high upon the overall stress/strain curve the working stress level is found. This is because the relationship between extension and tension is linear (Hook e's Law), while the relationship between tension and pitch is logarithmic, which means that the higher the working tension, the greater the extension needed to produce any given change in pitch. High stress therefore both improves tuning stability and makes tuning easier in general, since every degree of rotation of the tuning pin produces a smaller change in pitch.

15 The exact size of this safety margin is a debatable issue, though Adlung in his Musicae mechanica organoedi of 1768 clearly states that a harpsichord should be strung "so that the pitch can be safely raised a semitone. "Quoted in translation $\mathrm{i} n$ HubBard, Frank: Three Centuries of Harpsichord Making. Harvard, Harvard University Press, 1965, p. 281. Not only does this comment provide us with a working hypothesis for a safety margin, but it also supports the idea that makers thought about scaling and stress levels in terms of how many semitones a given string stood beneath its rupture load. 
of force applied to the string through extension, commonly measured in kilograms, while stress is the amount of force relative to the string's cross sectional area, often expressed in kilograms per millimeter squared $\left(\mathrm{kg} / \mathrm{mm}^{2}\right)^{16}$. Breaking stress or rupture load is the stress level at which a string will break, and it is this aspect - not tension per se - which the b uilder must consciously control in the design of his scale, for if he fails to keep the lengths within certain limits, he will not be able to tune the instrument to the desired pitch level before the strings break ${ }^{17}$.

The generally assumption among organologists has been that breaking stress is material-specific and does not vary with diameter. Heavier strings will require more tension to sound the same pitch at a given length, but the increase in tension will be xactly compensated by the increase in the string'crosssectional area. Putting it in practical terms, for any given string length, it is assumed that all diameters of the same material will break at the same pitch. Conversely, for any given pitch, all diameters should require exactly the same length to maintain any desired safety margin. Taking it one step further, then, since length and pitch are al ways exactly inversely proportional on a Pythagorean scale, the logical conclusion is that all diameters of a gi ven material located an ywhere on a Pythagorean scale are all equally close to breaking. Conversely, one can calculate that particular Pythagorean scale which is of sufficient length to achieve the desired safety margin for all diameters, and this scale can be seen as a sort of standardized maximum for the material, which can then be represented by the length of bit one note: $\mathrm{c}^{2}$.

As widely held as it is, the basic assumption which underlies this entire chain of logic isnot true. As wire is reduced to smaller diameters, it work hardens, exactly as when it is formed with a hammer and anvil. Therefore, breaking stress is not the same for all diameters of the same material, nor there is one single Pythagorean curve which represents the "maximum safe scale length" for ay type of wire" Smaller gauges are stronger relati ve to their area, and therefore will al ways be under-stressed on a Pythagorean scale, because the working stress level, which is constant, becomes ever lower compared

16 Common as they are in the literature, these units are not scientifically correct since they both use the (kilo)gram as a unit of force, while it is properly a unit of mass. Often an attempt is made to resolve this problem by using the unit of kilograms force $(\mathrm{kgf})$, though this is no real solution because it isgravity acting upon the specified amount of mass which is the operative force, and the force of gravity varies depending upon the distance from the center of the earth. Proper scientific usage is to represent tension in Newtons and stress or load in Pascals.

17 Stephen Birkett, who has been the first in modern times to attempt to reproduce music wire with the same metallugical composition as ancient wire, reports that his research indicates the the elastic limit of the wire ws just as much a limiting factor as rupture load (personal communication). The elastic limit is the point at which the wire be gins to permanently deform, which can be located anywhere along the stress/strain curve from several semitones up to a small fraction of a semitone belo w the rupture load. Strings with a low elastic limit will not break immediately, but rather at each tuning the y will be found to be slightly flat; after having been raised again numerous times, they will eventually break at the supposedly safe pitch le vel. As important at this aspect of the behavior of wire may eventually prove to be, the issue is far too complex to be dealt with here. See BIRKETT, Stephen: "Historical iron music wire and its practical modern replication as a viable commercial product", in Proceedings of the 2006 harmoniques International Congress, (in preparation).

18 As Goodway and Odell put it, "the choice of the gauge [diameter] of wire... is also choice of the strength of the wire." The italicized emphasis is that of the original authors. See G oodwAY, Martha, and Odell, Jay Scott: The Metallurgy of 17th-and 18th-century Music Wire. Stuyvesant, Pendragon, 1987, p. 63. Malcolm Rose iron wireType A, for example, reaches a pitch/length strength parity with his brass wire at a diameter of about $0,55 \mathrm{~mm}$, and from there on, progressi vely larger diameters of the ir on wire are actually weaker than the corresponding diameters in brass, meaning the iron w ould requiring a shorter scale. This turns the assumptions of modern organology completely upside down. 
to the rising load-bearing capability. The most highly stressed string will always be found at or just below the lowest note located within the Pythagorean zone, for it is precisely there that we find the fatal combination of the lar gest (and therefore the weak est) diameter with the longest o verall scale length ${ }^{19}$.

In fact, if a builder wants to keep his wire consistently critically-stressed, as is commonly assumed, he must use a non-Pythagorean progression in which the werall scale length is continuously augmented by an amount which is e xactly proportional to the increased strength introduced by each change to a smaller diameter. When we realize this, the issue is turned completely around.Actually, the question is not, "Why did some builders use non-Pythagorean scales?", but rather, "Why didn't all builders take advantage of tensile strength pick-up by intentionally emplo ying augmented (i.e non-Pythagorean) scales?" The answer depends some what on stringing material; brass wire e xhibits a much lo wer rate of increasing strength with decreasing diameter, so little that an y length adv antage to be gained is hardly w orth the ef fort of emplo ying a mar ginally-augmented scale. With the much higher pick-up rate of iron wire, however, the answer is most lik ely that many builders simply didn't care enough to go to the extra effort of testing all the various diameters of the wire and calculating the corresponding non-Pythagorean proportions required for a consistently-stressed scale. F or these b uilders, most notably the Flemish makers, it was far easier to keep to the simplistic mentality of ancient Pythagorean proportions, allowing them the further practical adv antage of using standard rulers mark ed in normal units of measure to position their bridges. The fact that the strings in the upper re gisters were understressed by two or three semitones was either unknown to them (though that is difficult to imagine) or of no consequence to them; otherwise, they would have designed their instruments differently.

Other builders, however, such as those whose instruments hre been presented here aboe, decided to take advantage of this e xtra strength, augmenting the length in order to gi ve their treble notes a cleaner, clearer, more singing tone. In that sense, the y were not only emplo ying a more sophisticated approach to the design of their scales, indicative of a more complete understanding and manipulation of the "ra w material" which is iron wire, b ut they were also more forw ard-looking, predicting the

19 In some cases, the most dangerous string will be found a fe w notes belo w the last Pythagorean-scaled note. This happens when a change to a heavier gauge occurs before foreshortening has had enough notes to accumulate a reduction in length that compensates the loss of strength.

Koster's assertion ("T raditional Iberian", op. cit., p. 15) that "because...the c ${ }^{2}$-equivalent lengths of the lo wer notes are shorter than that of the $\mathrm{c}^{3}$ string, the $\mathrm{c}^{3}$ string is generally that with the highest tension" is incorrect. While it is possible that an augmented $\mathrm{c}^{3}$ could have a higher tension than its relati vely shorter $\mathrm{c}^{1}$, this would only be true if the increase in diameter going down were proportional less than the increase in length going up. Man y instruments with survi ving gauge marks from a variety of building traditions as well as documentary e vidence indicate an average distribution of four gauges over the two octaves from $\mathrm{c}^{1}$ to $\mathrm{c}^{3}$, and according to an a verage of the various modern theories for the interpretation of Nurember $g$ wire gauges, this w ould represent a proportional increase in diameter of about five semitones. The augmentation of length for most of the instruments observed here is less than three semitones at $\mathrm{c}^{3}$, leaving a two semitone deficit. This means that the tension at $\mathrm{c}^{3}$ will inevitably be at least about $25 \%$ lower than that at $\mathrm{c}^{1}$. This "proportional shorthand" proof can easily be $\mathrm{v}$ erified by performing actual tension calculations for the two notes using real values and Taylor's Formula.

Koster may have confused tension for stress, in which case his statement has a higher chance of being correct, b ut it still would require at least some general statements about the assumed distribition of diameter and material. The important point is that there is no strict relationship which is true in all cases between scale length and either tension or stress in general termsAs the old adage goes, "the Devil is always in the details." 
practice found in man y late 18th and early 19th century pianos and ubiquitously from about 1870 onward. Modern pianos are generally built with augmented non-Pythagorean scales with octave ratios of about 1,9:1. As we shall soon see, the majority of the surviving Valladolid harpsichords indicate that their builders as well were among those looking forward toward the future rather than back towards the past, as proposed by Koster.

The Iberian harpsichords e xamined here consist of five out of K oster's six central instruments plus one other which was only briefly mentioned by him. Our examination will begin with the last of these, an instrument whose mak er is unknown, though he is thought to ha ve been from the pro vince of Salamanca ${ }^{20}$. Koster provides a plan view of the instrument and mentions that its scale is "suitable for brass strings throughout the compass", though no detailed description of the shape of the scale is given. Figure 5 demonstrates that this instrument is of the Type 1 scale design, having not only a short overall length $\left(c^{2}=274 \mathrm{~mm}\right)$ "suitable for brass", but also a strict Pythagorean scale all the way down to almost tenor $\mathrm{c}$, where a brief portion of foreshortening suddenly and rapidly leads directly to the bass "hook". Thus Iberian mak ers were perfectly capable of making instruments with strict Pythagorean proportions when they wanted to.

The other six instruments pro vide a variety of scale shapes, all of which are more or less nonPythagorean in their treble scales, some of them mark edly so. Therefore, the y are indeed unlik e either the generic "Italian" model (with short or long tail) or K oster's proposed generic "northern European" design. Ho wever, prepared as we no w are with a broader vision of northern $\mathrm{b}$ uilding styles, a ree xamination will show that we can e xclude four of these instruments from ha ving scales which might be characterized as demonstrating "a collecti ve indifference to the niceties of scaling as practiced almost everywhere else.” In so doing, an interesting detail will emege which may well prove useful for future studies re garding instruments of all kinds. Two instruments, ho wever, will remain stubbornly puzzling, one of which will be excluded from this study because of the uncertain nature of the data provided ${ }^{21}$. A possible explanation for the last instrument's markedly aberrant scale shape will be provided here, though by no means do I intend this hypothetical solution to be an ything other than that: possible guidelines for further lines of inquiry.

The anonymous instrument attributed to Fernandez Santos in the Museu de la Música de Barcelona (MDMB1495) is the easiest to e xplain ${ }^{22}$. Its scale, sho wn in Figure 6, is remarkably similar to the last two northern instruments illustrated abo ve; from tenor c upw ards, the scale follows a very strict logarithmic non-Pythagorean progression with an octa ve ratio of 1,88:1. The overall scale lengths among the three instruments are consistent within a range of less than one semitone, indicating that all three could well have been designed for the same general pitch $\left(\mathrm{a}^{1} \approx 415 \mathrm{~Hz}\right)$. The only difference is

20 The instrument is in private collection in the United States ofAmerica. String lengths, remnants of gauge markings, and other important information were kindly provided to me by John Phillips, who restored the instrument.

21 The excluded instrument is the 1750 Zeferino Fernández (Fundación Joaquin Díaz, Urueña) which at some point had been converted into a piano. Koster's string lengths are from his own reconstruction of the original state of the instrument.

22 String lengths were tak en by Martí Beltran with the assistance of the author during a recent e xamination of the instrument. 


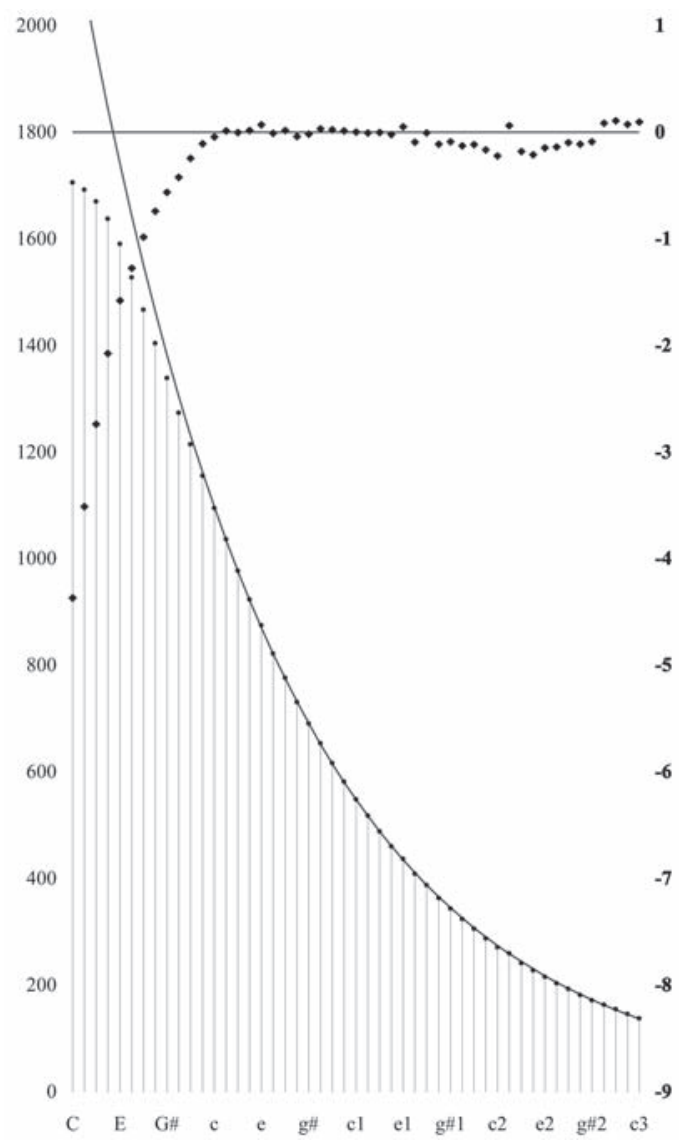

Figure 5. Anon. (Salamanca?).

that the Santos (attr) slope is a bit less steep than that of Gräbner andibaut, which is precisely why the maker was able to continue following this augmented scale right up to the top note without leeling-off at around $\mathrm{g}^{2}$, as in the other two. In all cases, the total augmentation found in the range of the smallest gauge (usually the highest 10 notes or so) is about three semitones relative to the length of tenor c. We can assume that all of these scales were designed to maintain a consistent stress le vel over the entire range of the instrument from tenor c upw ards, a supposition which is supported by an y number of believable solutions for an iron stringing schedule ${ }^{23}$.

23 The variety of dif ferent solutions possible according to dif ferent hypothetical diameter distrib ution schemes (i.e. "stringing schedules") and tensile strength pick-up rates is v ast, and I hesitate to cast doubt upon the general conclusion by presenting any one example which will inevitably contradict some minor detail of one or another author's interpretation of these variables. The dubious reader is invited to explore the matter and perform a variety of complete tension and stress calculations for these instruments employing values taken from a variety of sources, as I ha ve done, after which it will become ob vious that any solution based upon a generally accepted range of variables will be in general agreement with the analysis presented here. 


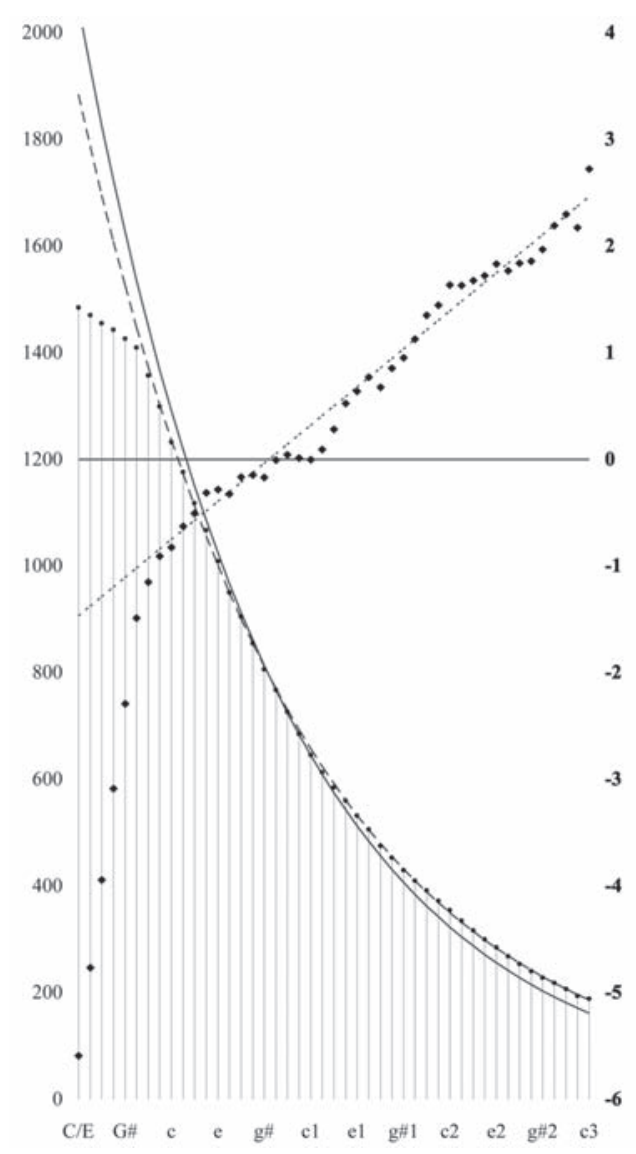

Figure 6. Santos (attr.), Barcelona.

The next two harpsichords are transposed instruments and therefore have markedly different scale lengths from all the others, the first sounding a quint pitch and the second at the octa $\mathrm{ve}^{24}$. Despite this difference in length, however, they both have remarkably similar scale shapes. As can be seen in figures $7 \mathrm{a}$ and $7 \mathrm{~b}$, tenor foreshortening clearly begins just below middle $\mathrm{c} 1$. The upper regions follow a non-Pythagorean curve which results in a total augmentation of approximately two semitones at the top note. The slight reduction in the total amount of augmentation is of little significance, as it would only mean that the builder wanted to have a slighter greater safety mar gin in the highest notes. What is peculiar is the $\mathrm{f}$ act that these progression are not re gular, as in the instruments seen abo ve. Any regular logarithmic progression will produce a straight upw ardly-sloping de viation trace, $b$ ut these instruments both e xhibit a curv e which sags do wnward in the middle of the o verall rise at the note

24 The instruments are Anonymous (probably Valladolid), Obradoiro Instrumentos Musicais, Lugo (K oster App.1/4) and Anonymous (probably Valladolid), museo Nacional de Antropología, Madrid (Koster App.1/5). String lengths used for the extrapolation are those reported by Koster. 
$\mathrm{c}^{2}$. It's possible that this peculiar shape is due to original $\mathrm{w}$ orkshop error or later distortion, $\mathrm{b}$ ut the remarkable similarity of the two scales would imply that it is an artifact of original intent. As we shall soon see, this particular shape is a direct product of the method by which these scales were most likly devised. This methodology, although commonly emplo yed in ancient instrument making, has no w been largely forgotten; curiously, despite a significant number of documentary references, it has also received almost no attention from modern organology.

As explained previously, the supposition that Pythagorean proportions produce the most natural model for the string lengths is not true if the instrument is strung in iron wire and the $b$ uilder wishes to maintain a reasonably-consistent level of stress. Under these conditions, he has no choicelt to consciously design a non-Pythagorean scale in such a manner that it is augmented in the highest notes by an amount proportional to the increase in strength between the thickst iron string in the tenor and thinnest string in the

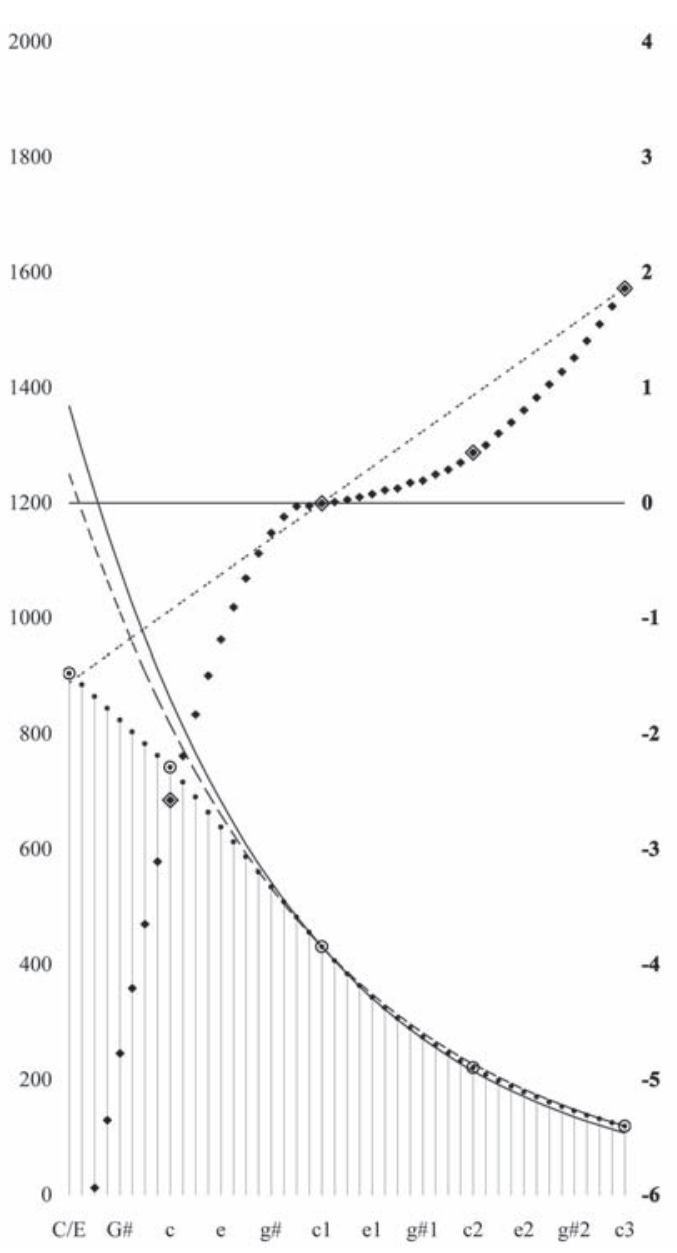

Figure 7a. Anon. Lugo.
2000

1800

1600

2

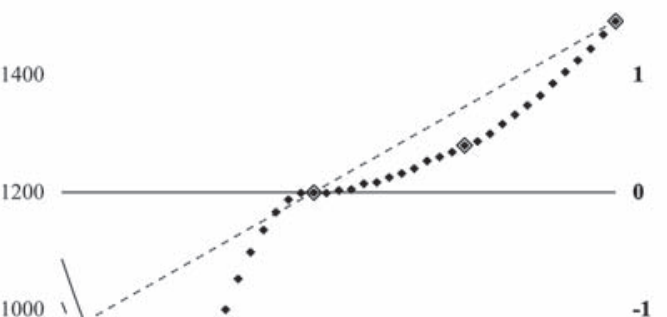

$-2$

$-3$

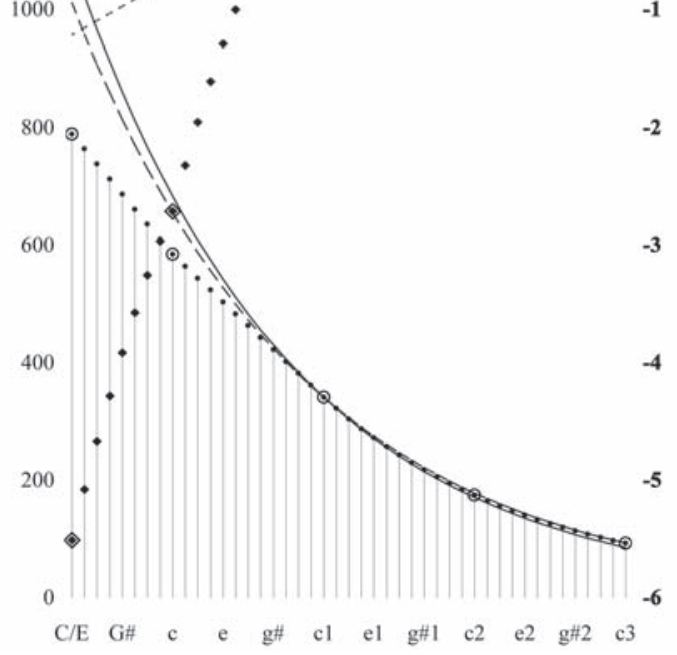

Figure $7 b$. Anon. Madrid. 
treble. While this may seem a daunting task for an ancient makr with no recourse to modern metallugical testing equipment, it is actually quite simple to achieve. The methodology was precisely described by the Viennese piano maker Jacob Bleyer in $1811^{25}$. Using a monochord, the builder first determines the "best" lengths for two notes at the top and bottom of the re gion which is to follow some sort of a regular curve, i.e. the re gion above the foreshortened tenor; in Ble yer's case, his k ey notes were tenor $\mathrm{f}$ and $\mathrm{f}{ }^{4}$. Bleyer did not state his criteria for defining "best", but it is safe to assume he meant the longest length with a reasonable safety margin. Once these tw o lengths are kno wn, the lengths of the interv ening notes were interpolated by constructing a "geometric series" between the tw o extremes. The method by which such progressions were calculated in ancient times was by employing a triangular geometric calculator (hence the term "geometric progression"), known among instrument makers as a diapason.

The use of the diapason to calculate the dimensions of pipes among 18th and 19th century French organ builders is well kno wn, as diapasons are illustrated and described in both l'Encyclopedié and Dom Bedos' famous exhaustive treatise of the subject ${ }^{26}$, as well as a number of lesser -known works. A diapason w as also illustrated to define the circumferences of a rank of or gan pipes in Arnaut von Zwolle's often-cited 15 th century manuscript, though he called it a figura fimbrie ${ }^{27}$. The diapason was also known and used in Spain in the design of both or gans and stringed instruments, as is pro ven by the following quotes ${ }^{28}$ :

"Diapasón [...] entre los or ganeros, es una declinación formada en un plano, que demuestra todas las longitudes, y latitudes de las fístulas, o caños del órgano, y por cuyas medidas se van cortando: su figura es la de dos líneas, que empezando con alguna anchura, caminan rectamente a unirse a un punto, aunque no llegan a él"'29.

- P. Esteban Terreros y Pando, 1786-1788, Diccionario Castellano con las Voces de Ciencias y Artes

“[...] para obtener la mejor bondad de los instrumentos, es muy importante poseer una re gla proporcionada, que los artífices llaman vulgarmente diapasón. Y no debe observarse esto tan sólo en las cuerdas, sino también en los tubos de los órganos, en los cuales, si han de tener la debida proporción, la longitud y la anchura de diámetro, de verán ser proporcionadas. Así lo hacen siempre los fabricantes de órganos" ${ }^{\prime 30}$.

- Francisco Salinas, 1577, De Musica Libri Septem

25 For a complete exposition of Bleyer's methodology, see Poletti, Paul: "Beyond Pythagoras: Ancient Techniques for Designing Musical Instrument Scales", in Keyboard Instruments - Flexibility of Sound and Expression - Proceedings of the harmoniques International Congress, Lausanne 2002. Bern, Peter Lang, 2004.

26 Bedos de Celles, François: L'Art du Facteur d'Orgues. Paris, 1754.

27 Bibliothèque Nationale, Paris, Ms lat.7295, folio 129.

28 Both quotes are found under the heading Diapasón in SAura BuIL, Joaquín: Diccionario Técnico-Histórico del Órgano en España. Barcelona, Csic, 2001.

29 "[...] among organ makers, it is a reduction in the form of a plan, which sho ws all the longitudes and latitudes of the pipes, or tubs of the organ and according to the measures of which they are cut. Its figure is that of two lines, which begin with a certain width [between them], running straight towards a point where they join, although they don't arrive at it'.

30 "To obtain the best quality of instruments, it is ery important that one poses a proportioned ruler which the makers call diapasón in the vulgar. And not only should this be observed in the strings, but also in the tubs of the organs, in which, they must have the proper proportion, the length and the width have to be proportioned. This is how the organ builders always do it". 
In both modern Spanish and Catalan, the ard has also come to mean the fingerboard of instruments such as the violin, the guitar or the lute, probably in reference to the proportional distances between the positions where one places the fingers or frets, a division which is exactly the same as that of the base line of an or gan maker's diapason. Diapason also means a standardized reference frequenc y and/or the tuning fork from which it can be taken, a definition shared by Italian, French, Portuguese, Catalan and Spanish ${ }^{31}$. However, of all these Romance languages, Spanish is the only one with an officiallysanctioned dictionary in which the ancient definition can still be found today:

"Regla en que están determinadas las medidas corvenientes, en la cual se ordena con debida proporción el diapasón de los instrumentos, y es la dirección para cortar los cañones de los ór ganos, las cuerdas de los clavicordios, etc." ${ }^{32}$.

This linguistic tenacity may well be an indication of the application of the diapasón to the problems of musical instrument design among Spanish makers which was even more common than in other European traditions.

Such a widespread and enduring popularity among musical instrument makers of all kinds would be well-deserved, for a diapason is a powerful and flexible tool, easy to construct, eminently practical in the w orkshop environment, and especially applicable to musical instruments in that it $\mathrm{f}$ acilitates calculations involving irrational numbers. With a diapason, there is no need whatsoe ver to define the diameters or lengths of pipes or strings in any local rational unit of measure, such as pulgadas, palmos or varas; dimensions can simply be transferred to it or taken from it by copying them directly from or onto the work at hand, or to a dedicated marking stick ${ }^{33}$. More important, it releases the b uilder from the intellectual bonds of the simplistic Pythagorean proportions observ able in the design of man $y$ Italian and Flemish instruments, allowing him to construct a wide variety of logarithmic progressions as well as complex irregular progressions, feats which might otherwise seem be yond the capabilities of "simple" artisans with no formal education in mathematics. Actually, considering the large number of dimensions needed for a rank of pipes and the f act that they progress by exceedingly fine degrees, it w ould literally be impossible to w ork in simple fractions of an y normal unit of measure. Or gan builders probably would have found the discrete unit methodology of the Flemish malers to be naively

31 For an exhaustive investigation of the various historical meanings in the French language, see D ONAHUE, Thomas: "A Proposed Method for Establishing a Preliminary Gauge P attern for Stringing Eighteenth-Century French Harpsichords", in The Galpin Society Journal, LXII (2009), pp. 141-157.

32 "A ruler on which the con venient measures are determined, according to which the proper proportion of the diapason [i.e. fretboard] of the instruments is ordered, and pro vides the guidance for cutting the tubs of or gans, the strings of cla vichords, etc." Diccionario de la Lengua Española, RAE, 22nd edition (2001) and the adv ance version of the 23rd edition (in preparation), via the web page of the RAE: http://www.rae.es/rae.html

33 That or gan builders certainly thought in this manner is demonstrated by another quote found under the entry for Diapasón in S AURA BuIL, Joaquín: op. cit., p. 172: "[...] un re xistro de trompeta de battalla de enttonación de doze palmos de la primera y las restatantes siguiendo su diapasón [...]" ("[...] a rank oftrompeta de battalla [i.e. "en chamade"] with an intonation of 12 palmos [i.e. an 8' rank] for the first [pipe] and the remaining [pipes] according to [the rank' s] diapason [...]"). - 1789, Miguel Alcarria, Albacete. Even a series of v ery large dimensions, such as the lengths or diameters of an entire rank of 16' or 32' organ pipes, can be devised on a diapason no larger than a modern A4 sheet by working to scale. 
simplistic, being as the $\mathrm{y}$ were completely accustomed to mo ving about within a $\mathrm{v}$ ast uni verse of numerically undefined dimensions which had been determined geometrically.

The precise nature of the progression obtained from a diapason is not al ways the same, ho wever. Depending on how the diagram is constructed and used, the results can either be a strictly logarithmic Pythagorean series (steps approximating $12 \sqrt{2}$ with lengths halving at the octa ve), a logarithmic nonPythagorean augmented progression (halving at interv als larger than the octa ve), or a wide $\mathrm{v}$ ariety of irregular series with progressively-increasing augmentation.Therefore, before considering the hypothesis that the scale of any particular extant musical instrument - be it an ogan, a harpsichord, clavichord, piano, or guitar - may ha ve been designed using a diapason, it is absolutely essential to understand the theory behind these geometric calculators as well as the shapes of curves they can produce.

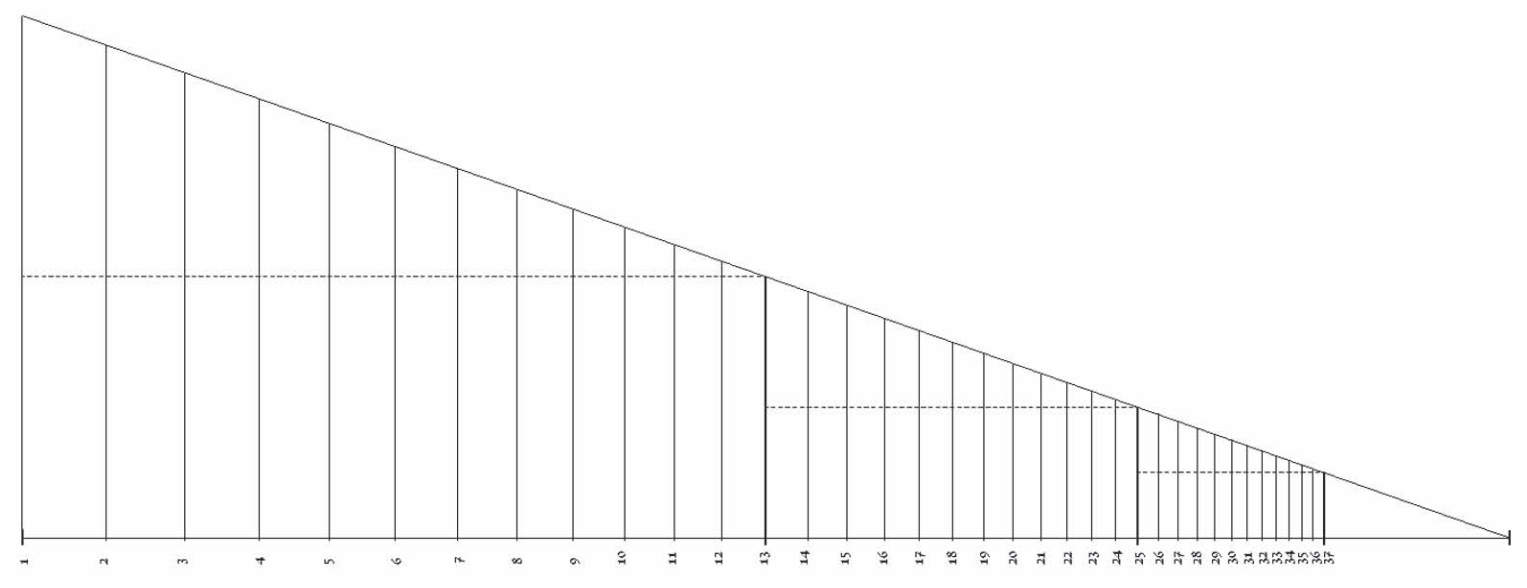

Figure 8. A basic Pythagorean diapason.

The simplest form of diapason is sho wn Figure 8. A horizontal line is dra wn at an y arbitrary length con venient for the medium, be it paper , parchment, or a w ooden board ${ }^{34}$. This line is then divided into tw o equal parts, and one part is again equally subdi vided, the process being continued until there are as many progressively-halved segments as the number of octa ves over which the scale is to be calculated. The longest of these segments is then partitioned into 12 proportional subsegments representing the 12 notes of a chromatic scale, after which the rest of the se gments are partitioned in a similar manner simply by halving the lengths along the line from the right end ${ }^{35}$. After the line is

34 The 1594 inventory and assessment of the valuables of the organ builder Andrés Gómez in Toledo contains the entry "dos tablas de diapasones", literally "two boards of diapasons". The fact that they were included is an indication of their status as one of the essential tools in the organ builder's workshop, and therefore a valuable asset. See SAuRA Buil, Joaquín: op. cit., p. 171.

35 The methods used for di viding the first se gment into 12 proportional steps were not necessarily al ways precisely logarithmic. Simple Pythagorean proportions were used both by Arnaut and Bedos; l'Encyclopedié offers both a "Just Intonation" solution, in volving the ratios of pure fifths, fourths, thirds and sixths, and an equally-proportional di vision (i.e. "Equal Temperament"), although the v alues given for the latter are not correct. In an y case, the slight irre gularities from step to st ep produced by the different methods are insignificant for the purpose of scaling. 
partitioned, the vertical leg of the triangle is added on the left. This first ordinate represents the first dimension of the series to be scaled, either in full size or at some simple scaled reduction (di vided by any convenient whole number). Finally, the triangle is completed by adding the hypotenuse, and the remaining ordinates are determined by dra wing lines upw ards to it from e very mark along the base line. The heights of the ordinates will follow whatever proportional series was used to partition the base line, in this case a (quasi)-Pythagorean series, in which the ratio between an y two adjacent elements is the ${ }^{12} \sqrt{2}$. Once the basic diagram is completed, an y number of scales can be calculated simply by marking a different height for the first ordinate and striking a new hypotenuse. In each and every case, the ordinates defined thereby will follow the same proportional reduction rate of ${ }^{12} \sqrt{2}$.

To the untrained e ye, all diapasons may appear to be alik e, but nothing could be further from the truth. While such a Pythagorean diapason illustrates the basic principle of geometric calculation, it had almost no application in the or gan building trade, since almost nothing in an or gan follows a strict Pythagorean scale ${ }^{36}$. Organ builders discovered long ago that man y dimensions of or gan pipes, primarily those relating to cross-sectional area and various mouth/reed dimensions, could not be scaled according to Pythagorean proportions, for if all dimensions of the pipes were simply haled or doubled at the octaves, the longer pipes w ould be too large and the shorter pipes too thin in order to function well and maintain a good overall balance of volume over the entire gamut ${ }^{37}$. Therefore they used scales in which these dimensions reduced more slo wly than by halving at e very 12 th step, that is, scales in which the lengths were gradually "stretched" or augmented compared to Pythagorean lengths, and their diapasons were especially constructed to produce these non-Pythagorean scales.

Figure 9 shows an example of a regular logarithmic augmented-scale diapason of the type which became common among or gan builders in the 19th century ${ }^{38}$. Here the halving distance is greater than the normal octa ve interval of a Pythagorean ${ }^{12} \sqrt{ } 2$ progression, which is achie ved by partitioning half of the base line into a series of proportional steps whose number is greater than 12 , in this case $14^{1} / 2$. Since the ratio between each successi ve step is ${ }^{14 \frac{1}{2}} \sqrt{2}$, starting from the ordinate at an y note, its half value can be found by counting up 141/2 steps (black arro ws have been added to mark the initial successive halving points along the base line). Organ builders have developed a common terminology which reflects this underlying logic; this scale w ould be referred to as "halving on the $151 / 2$ th" (note, or line on the diapason, inclusive the first). Any ${ }^{\mathrm{n}} \sqrt{2}$ can used as long as $n>12$. Exactly as with a ${ }^{12} \sqrt{ } 2$ diapason, the difficult task of partitioning the base line need only be done once, and other scales with

36 Not even the lengths of organ pipes follow an exact Pythagorean series, despite ubiquitous statements to the contrary. Length can be af fected by a lar ge number of construction and v oicing factors, but even when all of these are k ept as re gular as possible, the length at e very octave is slightly shorter than the theoretical Pythagorean length. The famous French organ builder Cavaillé-Coll developed a formula to more or less accurately predict the de viation between actual and theoretical (Pythagorean) length reduction rates. See Robertson, F. E.: A Practical Treatise on Organ-Building. London, 1897, p. 32.

37 Arnaut's use of a diapason to calculate a non-Pythagorean series for the circumferences of a rank of pipes which folweed a strict Pythagorean series in length shows that this was already common knowledge in the mid-1400 century.

38 Cavaillé-Coll, Aristide: De L'Orgue et de son Architecture. Paris, 1872. The work carries the following Advertisement: "Les documents contenus dans cette brochure ont déjà été publiés par nous en 1856 dans le quatorzième v olume de la «Re vue générale de l'Architecture et des Travaux Publics» de M. CÉzAr Daly." 
the same proportional reduction rate $b$ ut of differing overall lengths can be dra wn simply by adding more hypotenuses. As long as they all converge with the base line at its right-hand extreme, the ratios between any two ordinates defined by an y given hypotenuse will al ways be the same ratio used in the initial partition of the base line. Although there is no documentary e vidence for the construction of this type of scaling triangle before the 19th century , the f act that such re gular non-Pythagorean progressions were used by harpsichord mak ers is proven by the instruments e xamined above which have an upwardly-sloping deviation trace which follows a straight line ${ }^{39}$.

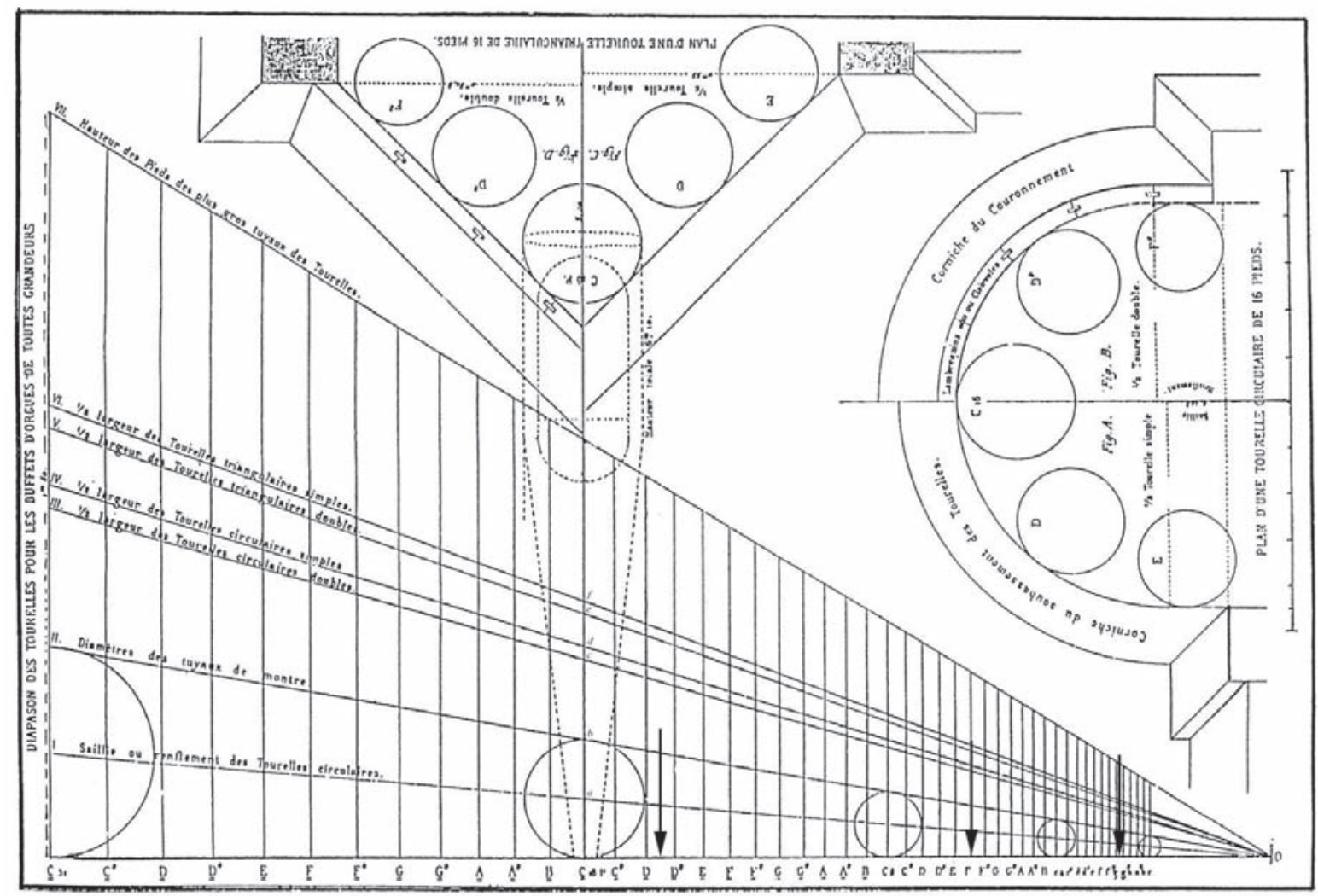

Figure 9. A rational regular non-Pythagorean diapason in which the dimensions halve after $141 / 2$ steps.

Before the 19th century, however, the most common type of or gan builder's diapason differed in both structure and result from such re gular designs. They are dra wn in a manner similar to a re gular diapason, be ginning by successi ve halving of the base line and further partitioning according to a based upon a spline curve. For a complete explanation of this process, see Pol et t i, Paul: "Beyond Pythagoras...", op. cit. 
(quasi) $^{12} \sqrt{2}$ series. The critical difference comes at the moment of drawing the hypotenuse; in this case, two dimensions are used to define two ordinates, those of the first and last pipe of the entire series, no matter how many intervening notes there are between them, and then the hypotenuse is dra wn by connecting their upper e xtremes ${ }^{40}$. However, since there is no agreement between the halving of the abscissae and the halving of the ordinates, the geometric unity which is the $\mathrm{v}$ ery essence of a normal diapason is destroyed. In reference to this critical diference introduced by the manner in which the slope of the hypotenuse is defined, I call this type of scaling diagram an " $\alpha \omega$ (alpha-omega) diapason".

Figure 10 shows a typical $\alpha \omega$ diapason, which is Figure 150 (Plate XIX) from Dom Bedos. Note that the base line is partitioned as in a re gular Pythagorean diapason, $\mathrm{b}$ ut exactly as described by Terreros y Pando in 1786, none of the various hypotenuses ${ }^{41}$ converge at the end point of the base line. If they were to be extended further until they were to cross an extension of the base line, an anarchical jumble of different convergence points would appear. The means that none of the ordinates defined by any one of the hypotenuses will follow a regular logarithmic progression.

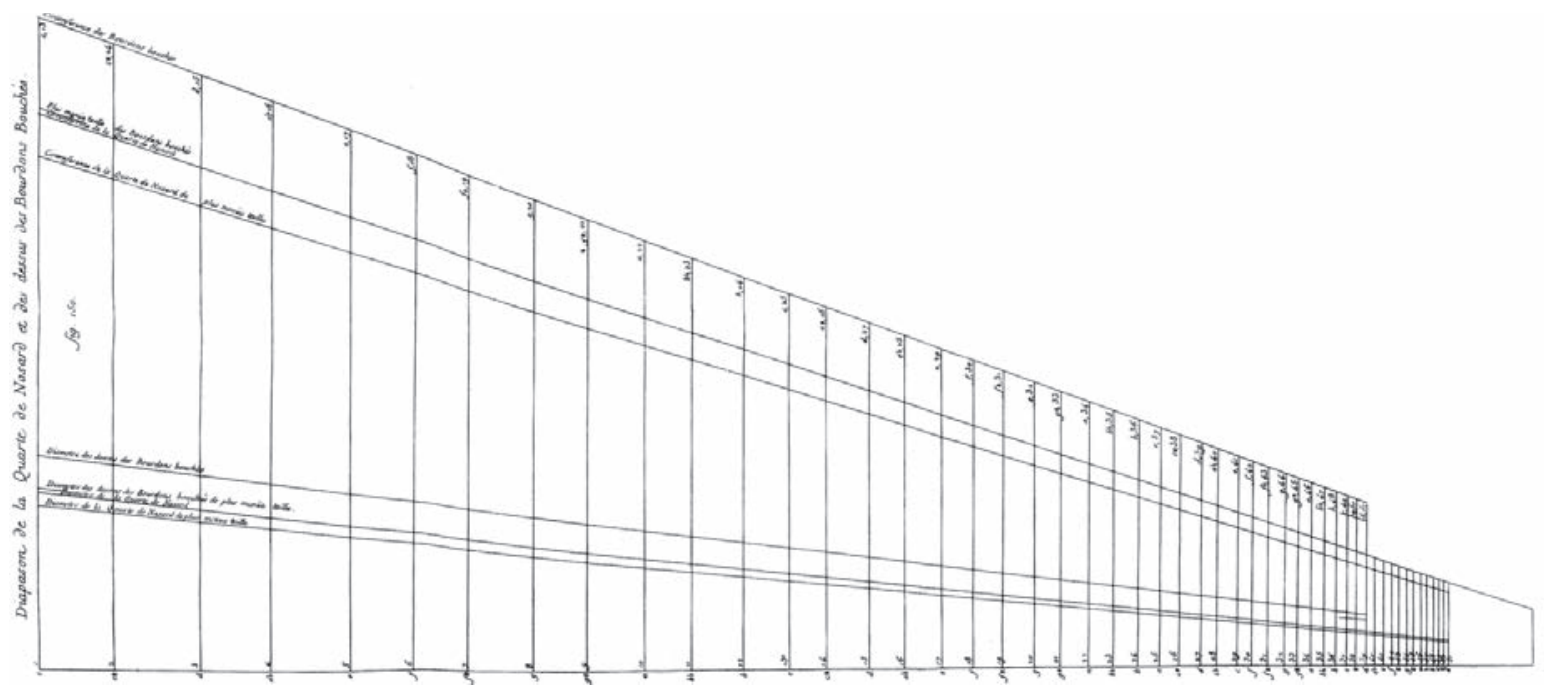

Figure 10. A typical $\alpha \omega$ diapason from Dom Bedos.

40 Bedos begins his instructions for the construction of a Diapason with a long and detailed description of the partitioning of the base line, using a Pythagorean chain of fourths and fifths for the first segment and successive halving for the remaining. He then continues: Pour les largeurs des tuyaux, une seule ligne les donnera toutes. Il faut avoir seulement celles de premier \& $d u$ dernier. (For the widths of the tubes, a single line gi ves them all. One only needs those of the first and the last [tube].) See Bedos de Celles, François: op. cit., pp.61-64 and plates XVIII-XIX. Arnaut's method is identical to that of Bedos with one exception: instead of defining the last pipe in the series, he defines the last ordinate at the right end of the diagram, which represents the dimension of a pipe which does not e xist, being an infinite number of octa ves above the first pipe. Nonetheless, the shape of his scale is identical to that of any normal diapason and can be accurately calculated by taking the ordinates of the first and last pipes from his figura fimbrie.

41 While it is technically incorrect to refer to the upper sloping side of such a trapezoid as a "hypotenuse", I shall continet to use this term both out of convenience and as a reminder that the basic logic of the $\alpha \omega$ diapason remains grounded in triangular geometry, even when this logic is purposely subverted. 
As this plate clearly illustrates, one can dra w different hypotenuses on an y pre viouslyconstructed $\alpha \omega$ diapason base, just as with the re gular diapasons, $\mathrm{b}$ ut in contrast, there is no guarantee that there will be an $\mathrm{y}$ correlation between the progressions defined by the $\mathrm{v}$ arious trapezoids. Each height/slope combination will interact in a diferent way with the logarithmic ${ }^{12} \sqrt{2}$ partition of the base line, creating an infinite number of irre gular progressions. Short of actually measuring each and every ordinate of each indi vidual $\alpha \omega$ diapason, it might seem an impossible task to predict the progression each defines, let alone arrive at a "General Theory" applicable to all possible $\alpha \omega$ diapasons. Luckily, understanding the geometry of $\alpha \omega$ diapasons and predicting the nature of the scales the $y$ define with mathematical e xactitude is far simpler than one might assume.

As mentioned above, the initial steps of partitioning the base line are identical for both the $\omega$ and the regular Pythagorean version. It has also been demonstrated that a strict Pythagorean triangle can result with an infinite variety of hypotenuse slopes as long as the base and hypotenuse both terminate in a single convergence point. Logically, then, for the hypotenuse of any irregular $\alpha \omega$ trapezoid, there also exists a theoretical Pythagorean triangle which would have a base line located at whatever height is required for convergence between its end and the end of the hypotenuse.This means that inside every $\alpha \omega$ trapezoid, there hides a reular Pythagorean triangle; finding the triangle is the ley to understanding the $\alpha \omega$ design.

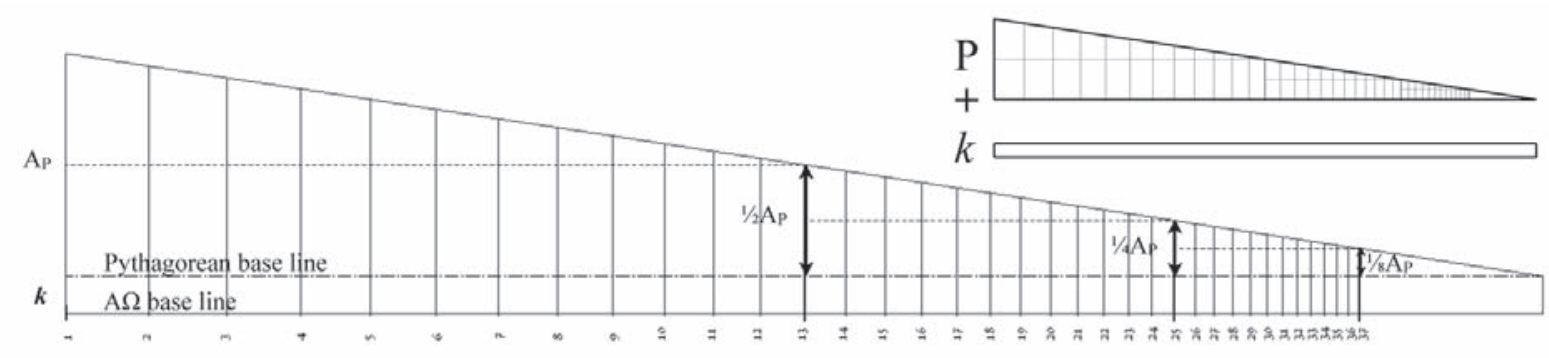

Figure 11. Deconstructing the $\alpha \omega$ Diapason trapezoid into its component parts: a regular Pythagorean right triangle poised atop a rectangle.

To find this hidden triangle, a ne base line is simply tended from the point where the hypotenuse meets the shorter of the tw o vertical sides of the trapezoid. This virtual base line restores the unity between the halving of the abscissae and the ordinates, as shown in Figure 11. Thus the $\alpha \omega$ trapezoid can be viewed as consisting of tw o components: a re gular Pythagorean triangle standing on top of a long rectangle. The series of dimensions it defines consists of the regular Pythagorean series $\left({ }^{12} \sqrt{2}\right)$ of the triangle augmented by a constant, $k$, which is equal to the height of the rectangle. In reference to this compound derivation, I will refer to such a series as a " $\mathrm{P}+k$ scale". 
The exact nature of each series depends on two design characteristics: the slope of the hypotenuse and the height of the rectangle relati ve to the height of the shortest ordinate defined by the triangle. In general, though, $k$ is usually relati vely small compared to the Pythagorean ordinates, $b$ ut as the regular triangle reduces in height, $k$ becomes ever more significant. If the progression is carried out far enough, the roles reverse, and the Pythagorean ordinates become much less significant compared to $k$, essentially eliminating any increment whatsoever between successive values. Therefore the scale of an $\alpha \omega$ diapason transforms itself from a quasi-logarithmic progression of near -identical proportions to a quasi-static succession of near-identical absolute values ${ }^{42}$. Considering this inherently metamorphic structure, the nomenclature " $\alpha \omega$ " acquires an additional significance, for these scales represent a continuos connection between the two opposing paradigms of stringed musical instrument design: the constant tension/varied length model, the basis of the harp and all harp-like instruments, including the clavichord, harpsichord and piano, and the constant length/varied tension model, the basis of the open strings of the lute, guitar, and violin families.

$\mathrm{P}+k$ scales have a distinct appearance when they are graphed as deviation from a Pythagorean series, as shown in Figures 12a and 12b. Figure 12a represents an analysis of three octa ves of the $\mathrm{P}+k$ series generated by the top line of the Bedos diapason illustrated in Figure 10, assuming tenor $\mathrm{c}$ as the starting note. The $x$ axis represents a normal regular Pythagorean progression, and the bold

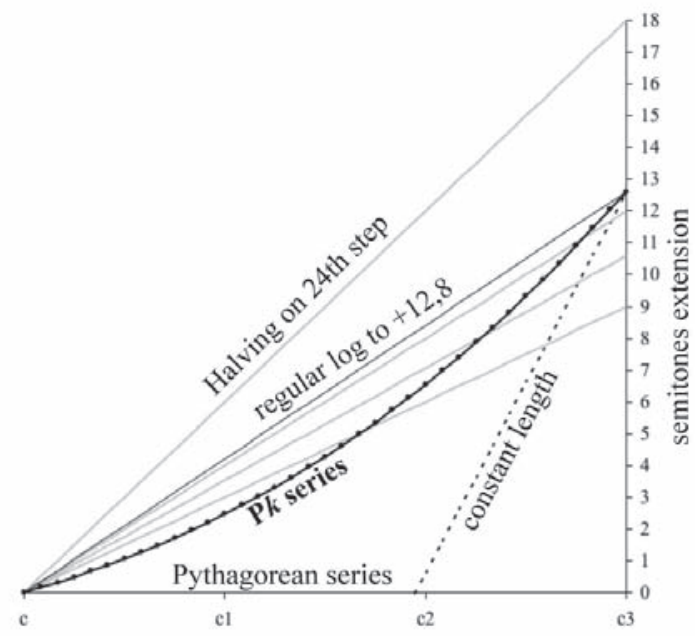

Figure 12a

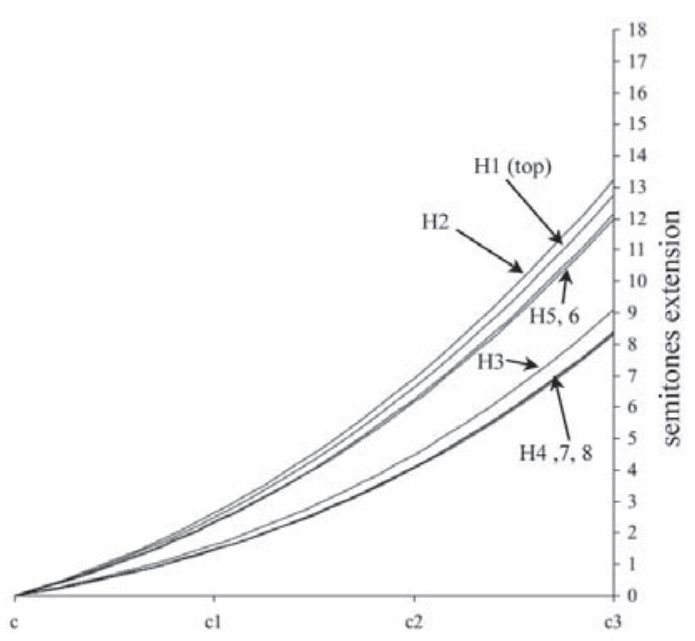

Figure $12 b$

42 I suspect that many ancient instrument makers did not understood the mathematical logic made evident by this analysis. For them, it was simply a practical method of creating a non-Pythagorean series of diminishing dimensions. Hwever, even without understanding the theoretical basis for the de vice, I have no doubt that ancient mak ers were well-versed in its use and certain ly would have had a vast empirical knowledge about the sort of scales produced by a variety of height and slope combinations. 
curved trace sho ws the $\mathrm{P} k$ curve. F or comparison, v arious other progression are also illustrated: the regular log series required to arrive at the same amount of augmentation at $\mathrm{c}^{3}$ (12,8 semitones); three common 19th century "rationalized" pipe scale progressions, halving on the 16th, 17th and 18th steps (light gray lines); the maximum historical pipe scale, halving on the 24th; and finally, a constant series using the length of $\mathrm{c}^{3}$ for all notes. The angles of approach where the $\mathrm{P}+k$ curve meets the Pythagorean scale and the constant length scale are similar, indicating the transformative nature of the curve, smoothly bridging the gap between the two extremes, and giving the $\mathrm{P}+k$ curve its unique shape: a downwardly-sagging curve. Figure $12 \mathrm{~b}$ shows the rest of the series generated by the various hypotenuses of the same diapason. While they all vary more or less from one another, they all share the same sagging de viation curve. Therefore, any time an augmented scale with a sagging curve is detected, the chances are high that the series was generated using an $\alpha \omega$ diapason. This is exactly the type of curv e which can found in the treble re gions of five of the seven Iberian harpsichords under discussion.

Armed with this kno wledge about the appearance of a scale generated by an $\alpha \omega$ diapason, the sagging curves of the two anonymous transposing instruments are no longer puzzling. Table 1 shows that the lengths of the reported key notes of these scales agree quite well with the corresponding alues of a $\mathrm{P}+k$ series.

Table 1. Agreement with $\mathrm{P}+k$ series.

\begin{tabular}{|c|c|c|c|c|}
\hline \multirow{2}{*}{} & \multicolumn{2}{|c|}{ Anon. Lugo } & \multicolumn{2}{c|}{ Anon. Madrid } \\
\cline { 2 - 5 } & Reported lengths & Best-fit $\alpha \omega$ diapason & Reported lengths & Best-fit $\alpha \omega$ diapason \\
\hline$c^{1}$ & 431 & $\alpha=429$ & 342 & $\alpha=341$ \\
\hline$c^{2}$ & 221 & 222,5 & 175 & 175,5 \\
\hline$c^{3}$ & 120 & $\omega=119$ & 93 & $\omega=93$ \\
\hline
\end{tabular}

Thus it $\mathrm{w}$ ould seem highly probable that these mak ers were in $\mathrm{f}$ act using or gan $\mathrm{b}$ uilders' methodology to produce mildly augmented treble portions of their scales. In so doing, thewere simply following a trend in instrument design which $\mathrm{w}$ as becoming gradually more common throughout the 18 th century, finally culminating in the common practice among late 19th century piano mak ers. Bleyer's 1811 description is echoed by Julius Blüthner in his Lehrbuch des Pianofortebaus, originally published in 1872, in which he instructs the no vice that the scale of the upper octa ves should not follow strict Pythagorean proportions, b ut rather should be augmented by as much as the "quality" 
of the wire allo ws"43. Slightly different methods are gi ven in dif ferent editions, the earliest being a strict logarithmic progression, while the 1886 edition gi ves a solution which is a $\mathrm{P}+k$ progression. This seeming indifference to the precise manner by which the scale is augmented is also seen in the Valladolid harpsichords, with Santos (attr.) Barcelona being strict logarithmic and the tw o transposed instruments being $\mathrm{P}+k$.

The remaining Iberian instruments do indeed mo ve further a way from an y set of hypothetical norms which might be derived by examining instruments of other traditions, and understanding them presents some very interesting challenges to the organologist. The scales of the Santos ${ }^{44}$ and the Bueno instruments are illustrated in Figures 13a and 13b. They are some what similar in that the upper tw o octaves are augmented non-Pythagorean progressions which appear to hre been designed from middle $\mathrm{c}^{1}$ upwards using an $\alpha \omega$ diapason, as shown in Table 2. The two upper octaves of the Bueno ${ }^{45}$ exhibit such an incredible de gree of agreement with a $\mathrm{P}+k$ scale that it $\mathrm{w}$ ould seem unlik ely to ha ve been designed by an y other method. The octave below, however, appears to ha ve been scaled do wnward from middle $\mathrm{c}^{1}$ by simple Pythagorean doubling. Both instruments have a puzzling dip in scale length between $\mathrm{c}^{1}$ and $\mathrm{c}$, as well as a slight rise just above the bass hook; these aberrations from the supposed

43 Blüthner, Julius: Lehrbuch des Pianofortebaues in seiner Geschichte, Theorie und Technik . Leipzig, 1872/1886. Blüthner's comments are highly informati ve both as to the moti vation and the process of emplo ying augmented scales, and are therefore worthy of reproduction in full here. He introduces the topic in both editions with the same text:

"Nur in den oberen Oktaven bestimmt man die Saitenlängen annähernd so, als wären alle Saiten gleich dick und gleich gespannt, d. h. man reducirt die Saitenlänge beim Aufsteigen um eine Okta ve auf die Hälfte,. Wie schon erwähnt, v erfährt man aber in der Regel nicht nach diesem Principe...sucht man nämlich im Allgemeinen die Mensur im Diskant zu vergrössern, so weit die Beschaffenheit der Saiten dies erlaubt, um denselben mehr Elasticität und den Tönen mehr Stärke und Gesang zu geben".s

(Only in the upper octaves does one determine the string lengths as if all strings were equally thick and equally tensioned, that is, one reduces the string length by half with every octave ascending. As already mentioned, one as a rule does not follow this principle...but one generally attempts to augment the treble scale as much as allowed by the quality of the wire, in order to give the same more elasticity, and to make the tone stronger and more singing).

Hereafter, the two editions differ. The 1872 text, found on p.116, is as follows:

"Die speciellen Längenbestimmungen sind hier sehr mannichf ach. Beispielsweise mögen die Zahlen hier Platz finden, welche Sievers (S. 65 und 66 des S. 97 citirten Buches) angiebt. Derselbe nimmt für das a der Stimmgabel (b) eine Länge von 370 Millimeter für den schwingenden Theil der Saite, bei Verwendung der Saitennummer 17. Der um eine Oktave höhere Ton a ${ }^{2}$ sollte dann blos 185 Millimeter Saitenlänge haben, wofür man ihm aber 194 giebt; ebenso bekommt a 102 Millimeter statt blos 97 und $\mathrm{a}^{4} 54$ statt nur 51 Millimeter".

(The exact determination of the lengths $\mathrm{v}$ aries quite a bit. As an example, the values given by Sievers will be tak en here. For the $a$ of the tuning fork $\left(a^{I}\right)$, he takes a length of $370 \mathrm{~mm}$ for the vibrating part of the string, using the gauge 17 . The $a^{2}$ one octave higher should therefore have a string length of only $185 \mathrm{~mm}$, b ut one gives it 194; likewise, $a^{3}$ gets $102 \mathrm{~mm}$ instead of 97 and $a^{4} 54$ instead of only $51 \mathrm{~mm}$.).

The 1886 text on p.101 differs:

"Für das a der Stimmgabel $\left(\mathrm{a}^{1}\right)$ nimmt man eine Länge von $40 \mathrm{~cm}$ für den schwingenden Teil der Saite an, $\mathrm{a}^{2}$ bekommt eine Länge von $21 \mathrm{~cm}, \mathrm{a}^{3}$ erhält $11 \mathrm{~cm}$ Länge, und a4 wird $6 \mathrm{~cm}$ lang genommen. Ob das Instrument kurz oder lang gemacht wird, hat auf die Saitenlänge dieser 4 Okta ven keinen Einfluss. Die Saitenlänge der Bassokta ven richtet sich lediglich nach der Länge der Instruments".

(For the $a$ of the tuning fork $\left(a^{1}\right)$, one takes a length of $40 \mathrm{~cm}$ for the vibrating part of the string, $a^{2}$ gets a length of $21 \mathrm{~cm}$

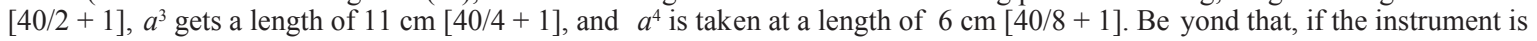
made short or long, this has no influence of the length of the strings of these four octa ves. The string lengths of the bass octa ves are determined by the length of the instrument).

44 Andrés Fernandez Santos, Valladolid, 1728. Collection of Fernanda Giulini, Briosco.

45 Joseph Bueno, Valladolid, 1712. Fundación Joaquin Díaz, Urueña. 
design logic are probably simply due to the spline curve ${ }^{46}$ which naturally results from connecting the key note lengths.

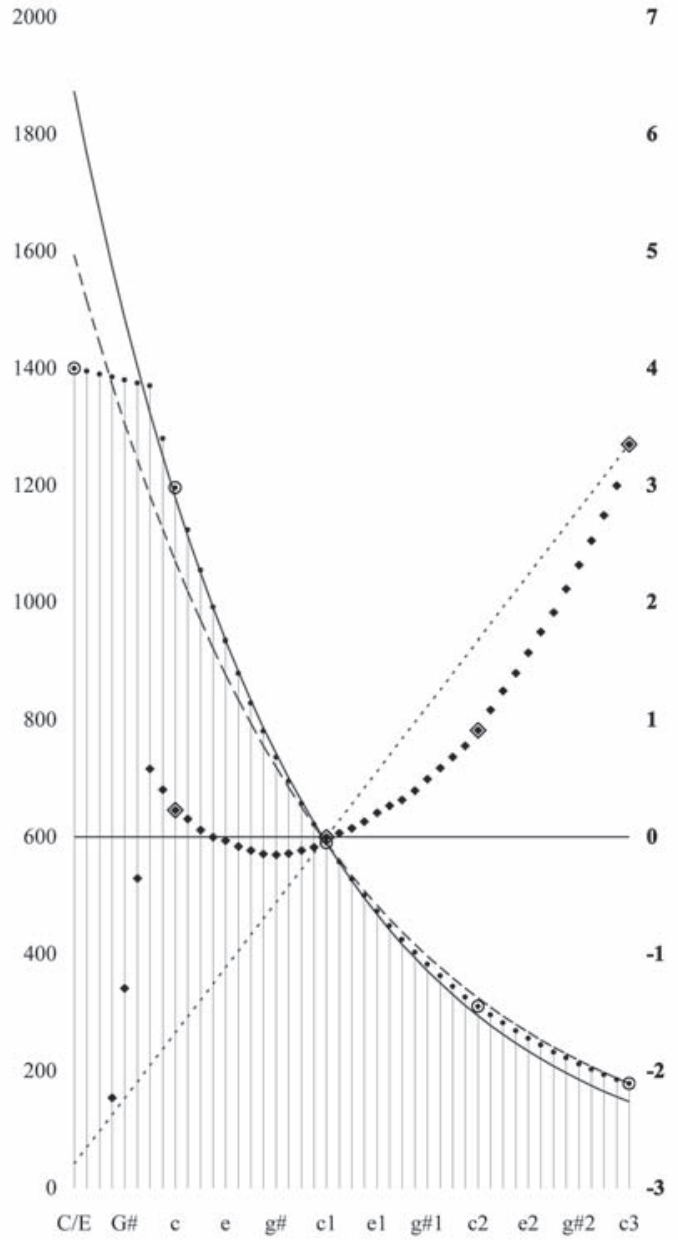

Figure 13a. Santos, 1728.

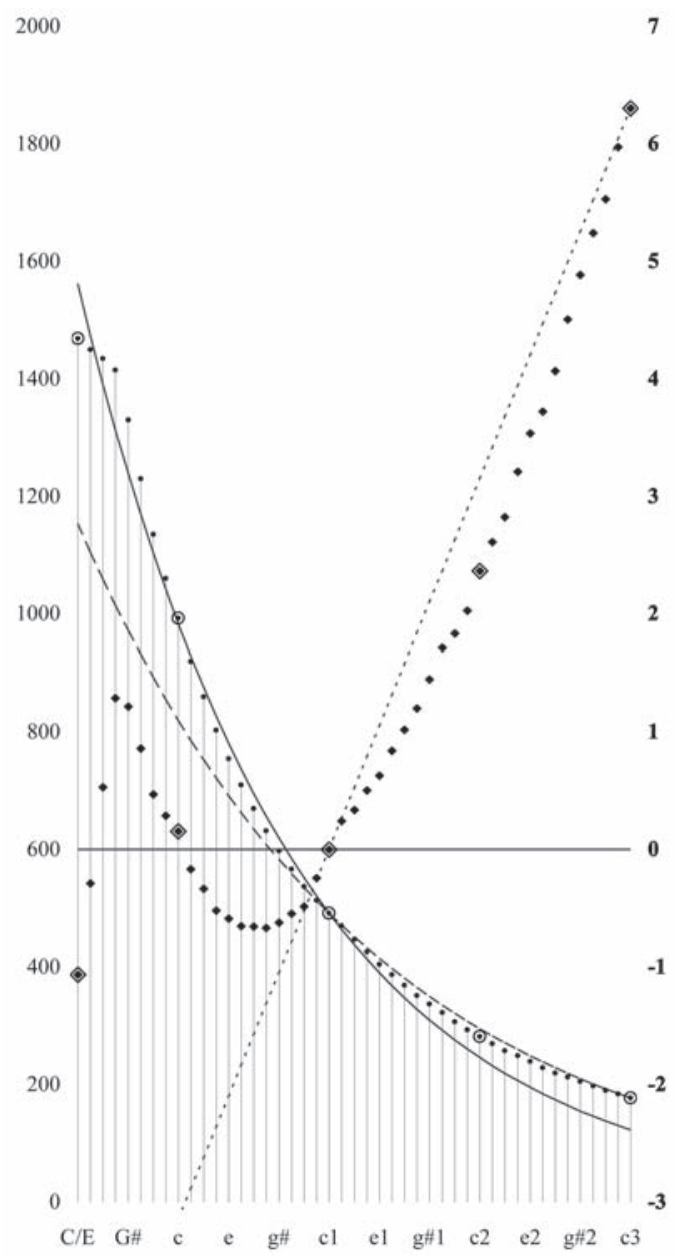

Figure 13b. Bueno, 1712.

46 The bridge on a harpsichord follo ws the mathematical shape called a spline curv e precisely because it is an e xample of the object from which the term is deri ved, a "spline": a w ooden batten or other thin semi-rigid object which has been bent $t$ o follow a series of points. Any spline will always adapt somewhat gradually to any change of vector precisely because its capability to suddenly alter course is limited. 
Table 2. Agreement with $\mathrm{P}+\mathrm{k}$ scales.

\begin{tabular}{|c|c|c|c|c|c|c|}
\hline \multirow{2}{*}{} & \multicolumn{3}{|c|}{ Santos } & \multicolumn{3}{c|}{ Bueno } \\
\cline { 2 - 7 } & $\begin{array}{c}\text { Reported } \\
\text { lengths }\end{array}$ & $\begin{array}{c}\text { Best-fit } \alpha \omega \\
\text { diapason }\end{array}$ & $\begin{array}{c}\text { Pythago- } \\
\text { rean length }\end{array}$ & $\begin{array}{c}\text { Reported } \\
\text { lengths }\end{array}$ & $\begin{array}{c}\text { Best-fit } \alpha \omega \\
\text { diapason }\end{array}$ & $\begin{array}{c}\text { Pythago- } \\
\text { rean length }\end{array}$ \\
\hline $\mathrm{c}$ & 1196 & & 1180 & 984 & & 993 \\
\hline $\mathrm{c}^{1}$ & 590 & $\alpha=588$ & 590 & 492 & $\alpha=492$ & 492 \\
\hline $\mathrm{c}^{2}$ & 311 & 314 & 295 & 282 & 282 & 246 \\
\hline $\mathrm{c}^{3}$ & 179 & $\omega=177,5$ & 147,5 & 177 & $\omega=177$ & 123 \\
\hline
\end{tabular}

While the design methodology of these instrument seems to be identical, the results, however, are drastically different. The scale of the Santos, much like the trio of Tibaut/Gräbner/ Santos (attr.) Barcelona instruments seen abo ve, is proportionally longer than tenor c by about three semitones at the top note. As has been sho wn, this amount of augmentation is perfectly understandable when the builder has chosen to profit from the increased strength of the smaller sizes of iron wire. The Bueno, however, has an astounding amount of more than six semitones augmentation, which is $\mathrm{f}$ ar too lar ge to be attrib utable to the e xploitation of an y reasonable amount of tensile strength pick-up ${ }^{47}$.

Whenever a scale is found which is as se verely augmented as is the case here, one possible explanation is that the instrument originally had the same number of string choirs distrib uted among a narrower range with the inclusion of sub-semitones, often called "double sharps". The additional choirs needed for the non-enharmonic notes would require a partition of the octave into more than 12 steps. As Koster points out, the range of $\mathrm{C} / \mathrm{E}$ to $\mathrm{a}^{2}$ (42 notes) was quite common in Iberian keyboards of the 17th century. If the current 45-note range of $\mathrm{C} / \mathrm{E}$ to $\mathrm{c}^{3}$ where reduced to the earlier span, three extra choirs w ould appear. One solution might be to gi ve one e xtra accidental to each of the three octaves, most likely an ab in addition to the standard meantone g\# ${ }^{48}$. However, while doing so might help reduce the excessive augmentation of the upper two octaves, it would only make the dip between tenor $\mathrm{c}$ and middle $\mathrm{c}$ w orse. In order to reduce the e xcessive augmentation, a solution w ould have to be found which places all of the extra notes above middle c. Another reason why they might be found only in the upper octaves is that such chromatic notes would be primarily used as thirds or sixths, and never as the roots of triads.

47 The missing string lengths of the Bueno were interpolated using the averages of lengths derived by two techniques: the measurement of intervening pixels between nut and bridge pins on a hi-resolution scan of the plan photograph, and a curve match between an Excel generated log plot and a transparent overlay of Koster's log plot expanded to A4 size, both methods working in full screen mode on a 19 " vertical monitor.

48 Praetorius, for example, centers his discussion of modified meantone temperament schemes on the problem of the bad

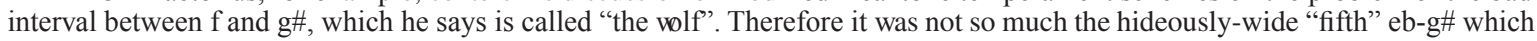
bothered 17th century musicians, but rather the overly narrow minor third, most likely because it deprived the key of $\mathrm{c}$ minor of a usable subdominant triad. See Praetorius, Michael: Syntagma musicum. Vol II: De organographia. Wolfenbüttel, 1618 , p. 155. 
A close examination of the plan photograph gi ven by Koster suggests that the 8' string for the highest note has been added later. There is not quite enough room at the top of the bridge to maintain the normal spacing between the last bridge pin and the penultimate pin, and therefore last choir spacing is too narro $\mathrm{w}$ at the bridge, the string running at an ob vious oblique angle to provide sufficient space for the jacks at the gap. The hitchpin is also squeezed into the tiny space in the bentside/cheek corner, being very close to the pin for the note b. Likewise, the tuning pin also seems to be uncomfortably close to the inside of the cheek. On the 4' bridge, it appears that the lowest note is also pinned at a reduced spacing, being only about $70 \%$ of the a verage distance for the four notes immediately above it. At the 4' nut, the second string is pinned at a distance from the bass end which is more or less equal to distance between top pin and the treble end of the nut. All of this implies that thelowest 4' string was also a later addition. The instrument may have originally had the range of $\mathrm{C} / \mathrm{E}$ to $\mathrm{a}^{2}$ with tw o sub-semitones in the treble (44 notes), one each for each of the upper tw o octaves, with both choirs plucking left. At some later time, the mo ve to modified meantone temperaments made the use of sub-semitones obsolete, and a lar ger compass to $\mathrm{c}^{3}$ had also become prevalent. To convert the instrument, an extra string was added to the top of the 8' and the bottom of the 4', extra mortises were made at the bottom of both reisters, and the 8' jacks were turned facing right. Naturally, since the spacing at the tails would be one semitone too wide where each sub-semitone was removed, a new keyboard would have to be made, removing any traces of the original compass in the process.

I w ould be the first to admit that such a suggestion should be tak en as nothing more than hypothesis until the instrument itself could be e xamined more carefully. In an y event, it is well known that a number of survi ving instruments ha ve indeed under gone such a transformation, so it is by no means outside the realm of possibility . In light of this $\mathrm{f}$ act, reconstructing the original design process using a diapason to calculate the string lengths is atremely instructive, for it not only demonstrates the vast difference between working in this manner and the usually assumed method of devising string lengths, but it also shows how the results can vary depending on the exact procedure chosen.

From the v ery be ginning, the use of a diapason is fundamentally dif ferent from the Douwes/ Ruckers approach, for the need to concei ve of the upper re gions of the scale as a block of multiple whole octaves is eliminated. By definition, the values used for an $\alpha \omega$ diapason can be separated by any number of notes. Therefore, even though the top note of the instrument is a, there is absolutely no need to think of the rest of the key notes as lower octaves of the top a. While this may seem illogical to those accustomed to the Ruck ers tradition, documentary e vidence indicates that or gan builders did indeed think this way ${ }^{49}$. Thus the hypothetical task of designing the upper notes of an instrument which ends with $\mathrm{a}^{2}$ can just as well begin from middle $\mathrm{c}^{1}$.

49 Almost all the diapasons illustrated in Bedos, for example, cover a span of four octaves and a major second, from $c$ to $d$ (octave identity unspecified), although some include one octave less and are labeled as starting on note 13. 
Let us suppose that the builder has tested his wire on a monochord and found that the diameter for the highest notes breaks at a pitch two semitones higher than the thicker diameter he will use at $\mathrm{c}^{1}$, and therefore he wants to augment his scale at $a$ by two semitones. Furthermore, he has determined that the ideal length for $\mathrm{c}^{1}$ which provides the desired safety margin is 28 local units, so 28 will be his $\alpha$ value. His first step, then, is to discover the value of $\omega$ for $\mathrm{a}^{2}$. To do this, he marks 28 units on the first vertical line $\left(c^{1}\right)$, counts up to the 25 th line $\left(c^{3}\right)$, marks 7 units (28/4), and places a straight ruler connecting these two dots. The hypotenuse hereby defined gives him a Pythagorean scale, a representation of any equal absolute stress situation for all diameters.Then, starting at the line for a (line 22), he counts back two notes to the left to $\mathrm{g}^{2}$ (line 20), sets his compass to this length of this ordinate, and transfers this dimension to line 22 , effectively stretching the length for the note $\mathrm{a}^{2}$ by exactly two semitones. He now has his $\alpha \omega$ values and is ready to proceed with the rest of the scale. Exactly how he does so, however, will produce subtly different solutions.

When an or gan builder wants to scale the widths or diameters of a rank of pipes with subsemitones, he need not include the e xtra notes in his calculation, for he can simply use the same dimension for both pipes. Of course, he may well choose to mark an extra ordinate very close to the normal accidental, but the difference between ideal dimensions for $\mathrm{g \#}$ and ab will be e xceedingly fine, hardly worth the effort ${ }^{50}$. The harpsichord maker, however, must choose between two options; he can either ignore the fact that a diapason gives dimensions for all of the notes of the series, working like some makers in other traditions and using only one k ey note per octave to position his bridge, or he can tak e advantage of the diapason's complete calculating capability and use more than one note per octave, increasing the precision of his bridge placement. If he choses for the former he can forget about the extra notes and simply count up the same number of lines as normal found between his key notes (inclusive) to find each length. The spline curve which the bent bridge describes will automatically a verage out the irre gular distribution of note lengths around the added accidental, much in the same manner that a diatonic harp neck often follo ws the shape of Pythagorean curv e even though the pitch dif ference between successi ve notes is sometimes a whole step and other times a half step, creating localized jumps abo ve and below a true Pythagorean progression in the actual string lengths. However, is he choses to use some other note near the middle of each octa ve, he must take the extra choirs for the sub-semitones into account. In this case, he w ould have count up the same number of lines as the actual choirs of strings in each octa ve, including the extra subsemitones.

50 Bedos, for example, first partitions the base line of his generic diapason by a series of ratios for pure fourths and fifths

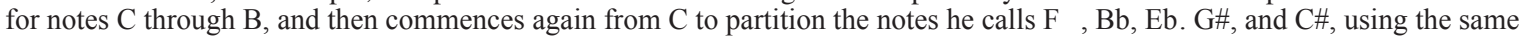
proportions. In strict temperament terms, this would correctly give the positions of $\mathrm{Ab}$ and $\mathrm{Db}$. Not only did he intermix his sharps and his flats, but he is also using the method for determining a Pythagoreantuning in a time when the applied temperament would have undoubtedly been either $1 / 4$ comma meantone or some $\mathrm{v}$ ariant thereof (temperament ordinaire). Thus it is ob vious that the fine nuances of proportional calculation required for temperament do not translate to the considerably coarser process of scalin $g$. See Bedos de Celles, François: op. cit., pp. 61-63. 
Table 3

\begin{tabular}{|c|c|c|c|c|c|c|c|c|c|}
\cline { 2 - 10 } \multicolumn{1}{c|}{} & \multicolumn{3}{c|}{ Option 1 } & \multicolumn{3}{c|}{ Option 2 } & \multicolumn{3}{c|}{ Option 3 } \\
\hline note & Abs. & L & aug./s.t. & Abs. & L & aug./s.t. & Abs. & L & aug./s.t. \\
\hline $\mathrm{c}^{1}=\alpha$ & 1 & 28 & $-/-$ & 1 & 28 & $-/-$ & 1 & 28 & $-/-$ \\
\hline $\mathrm{c}^{2}$ & 13 & 14,72 & 0,9 & 14 & 14,60 & 0,7 & 15 & 14,46 & 0,6 \\
\hline $\mathrm{a}^{2}=\omega$ & 22 & 9,34 & 2,0 & 24 & 9,34 & 2,0 & 26 & 9,34 & 2,0 \\
\hline
\end{tabular}

Table 3 give the result of the different methods for a scale with both one and tw o sub-semitones per octave. Option 1 sho ws the $\mathrm{v}$ alues for the $\mathrm{k}$ ey notes $\mathrm{c}^{1}, \mathrm{c}^{2}$, and $\mathrm{a}^{2}$ for the one note per octa ve approach, using 22 lines on the diapason from the first to the last note (inclusive). Option 2 shows the same values for a multiple k ey note approach with one sub-semitone per octa ve, using 24 lines total, and Option 3 the same approach applied to a tw o sub-semitone plan (eb/d\# and g\#/ab), requiring 26 lines ${ }^{51}$. Note that in each case, the value for $\mathrm{c}^{2}$ is different, becoming progressively shorter and having progressively less augmentation relevant to a Pythagorean length. Needless to say, if these instruments were later converted to a 12-tone chromatic layout, each option would result in a subtly different curve shape and length $\mathrm{v}$ alues for any assumed key notes. The differences are small, $\mathrm{b}$ ut they may be just enough to throw a researcher off the track when trying to understand how the scale was devised.

This hypothetical glimpse into an ancient instrument maks workshop serves primarily to illustrate the complexity of attempting to de vise an explanation for those scales which in no credible $\mathrm{w}$ ay can be seen as being based on Pythagorean proportions. The fact that such an undertaking is comple $\mathrm{x}$ is no reason not to attempt it, ho wever. Before doing so, ho wever, collectively as modern researchers, we would be well-served by pondering the old adage: When the only tool you have is a hammer, every problem looks like a nail. If our analytical tools are based on the a priori assumptions of the ubiquitous adherence to whole units or simple fractions of local measuring units, the calculation of string lengths by elementary Pythagorean proportions, and the use of primary $\mathrm{k}$ ey notes which are always octaves of the top note, and if the method of graphical representation used to e valuate scale shapes minimizes the visual impact of aberrations from the assumed Pythagorean design curve rather than making them obvious, then the objectivity of the examination will be undermined from its inception. This very real and present bias is unfortunately further enshrined and codified by the common museum documentation practice of measuring and reporting only those strings assumed to be key notes - usually octaves of the note $\mathrm{c}$, sometimes with octaves of the note $\mathrm{f}$ - leaving the unfortunate researcher who cannot personally examine the instrument with no choice $b$ ut to interpolate the rest of the scale. Naturally, whenever a

51 These are the two most likely place were sub-semitones would be added, for they are the most common places were the missing accidentals in meantone would be problematic. As already mentioned, ab is need to for the subdominant in $\mathrm{c}$ minor, and $\mathrm{d} \#$ is needed for the dominant in E major. 
scale comes under examination which was created using some entirely different method, the dogmatic nature of this chain of assumptions prevents us from detecting any telltale patterns which might lead to other explanations. Under such conditions, the only remaining resort might well appear to be to reach back to archaic practices in order to justify theories based on geometric coincidences ${ }^{52}$. It may well be true that some Iberian harpsichord mak ers were so lacking in an y real theoretical and/or practical sophistication regarding scale design that they needed to resort to such techniques, but this would seem rather unlikely considering that man y of them were also or gan builders, and even the smallest or gan requires that one operate on a conceptual le vel which is far beyond that needed to figure out a set of string lengths for a harpsichord. In any event, before we accept the proposition that this w as the case, it would behoove us to exhaust all other possible explanations first, especially those for which ample documentary evidence exists.

Recibido: 10/07/2009

Aceptado: 10/07/2009

52 It is common knowledge that any three points can be connected by a circular arc. It just so happens that when a scale is more or less augmented, three points tak en at the top, middle and bottom of the consistently-scaled treble portion can almos $t$ always be connected by a circular arc which very accurately follows the shape of the bridge. Using a variety of methods, including CAD drawings and plan photographs with digital o verlays, I ha ve been able to match circular arcs with the bridge shapes of a number of 19th-century fortepianos of $51 / 2,6$ and $6 \frac{1}{2}$ octa ves with a de gree of agreement every bit as good as that of the Bueno harpsichord over a range of up to 3 octa ves in the largest instruments. In fact, were it not for the kinks beneath e very strut of the cast iron frame, the upper three to four octaves of a modern Steinway would also very closely follow a circular arc. Therefore, the fact that this can be done is a demonstration of nothing except a geometrical coincidence. 
